\title{
Close Homolog of L1 and Neuropilin 1 Mediate Guidance of Thalamocortical Axons at the Ventral Telencephalon
}

\author{
Amanda G. Wright, ${ }^{1,2}$ Galina P. Demyanenko, ${ }^{1,2}$ Ashton Powell, ${ }^{2}$ Melitta Schachner, ${ }^{3,45}$ Lilian Enriquez-Barreto, ${ }^{1,2,7}$ \\ Tracy S. Tran, ${ }^{6}$ Franck Polleux, ${ }^{2}$ and Patricia F. Maness ${ }^{1,2}$ \\ ${ }^{1}$ Department of Biochemistry and ${ }^{2}$ Neuroscience Research Center, University of North Carolina School of Medicine, Chapel Hill, North Carolina 27599, \\ ${ }^{3}$ Universitaet Hamburg, D-20246 Hamburg, Germany; ${ }^{4}$ New Jersey Professor of Spinal Cord Research, Keck Center for Collaborative Neuroscience, \\ Department of Cell Biology and Neuroscience, Rutgers University, Piscataway, New Jersey 08854, ${ }^{5}$ Sino-German Center for Neuroscience, Dalian Medical \\ University, Dalian 116011, Liaoning Province, China, ${ }^{6}$ Department of Neuroscience, Howard Hughes Medical Institute, John Hopkins University School of \\ Medicine, Baltimore, Maryland 21218, and ${ }^{7}$ Instituto de Neurociencias de Alicante, 03550 Alicante, Spain
}

We report a cooperation between the neural adhesion molecule close homolog of L1 (CHL1) and the semaphorin 3A (Sema3A) receptor, neuropilin 1 (Npn1), important for establishment of area-specific thalamocortical projections. CHL1 deletion in mice selectively disrupted the projection of somatosensory thalamic axons from the ventrobasal (VB) nuclei, causing them to shift caudally and target the visual cortex. At the ventral telencephalon, an intermediate target with graded Sema3A expression, VB axons were caudally shifted in $\mathrm{CHL}^{-}{ }^{-}$embryos and in Npn1 ${ }^{\text {Sema-l- }}$ mutants, in which axons are nonresponsive to Sema3A. CHL1 colocalized with Npn1 on thalamic axons, and associated with Npn1 through a sequence in the CHL1 Ig1 domain that was required for Sema3A-induced growth cone collapse. These results identify a novel function for CHL1 in thalamic axon responsiveness to ventral telencephalic cues, and demonstrate a role for CHL1 and Npn1 in establishment of proper targeting of specific thalamocortical projections.

Key words: thalamocortical; axon guidance; cell adhesion molecule; semaphorin; neuropilin; somatosensory

\section{Introduction}

L1 neural cell adhesion molecules (L1-NrCAMs) are immunoglobulin-class recognition proteins that promote axon growth and migration in developing neurons (Maness and Schachner, 2007). The mammalian L1 family consists of L1, close homolog of L1 (CHL1), NrCAM, and neurofascin. CHL1 is unique among L1-CAMs in exhibiting a high caudal to low rostral gradient in the neocortex (Hillenbrand et al., 1999; Liu et al., 2000; Demyanenko et al., 2004). Molecules with graded expression are candidate axon guidance determinants, regulating topographic projections in the CNS.

Proper topography of thalamocortical axons requires guidance decisions at cortical and subcortical levels. Thalamocortical mapping is initially specified by transcription factors exhibiting graded expression in the thalamus [neurogenin-2 (Seibt et al., 2003); Gbx2 (Hevner et al., 2002)], the ventral telencephalon [VTe; Dlx1/2, Ebf1, Mash1 (Tuttle et al., 1999; Garel et al., 2002)],

\footnotetext{
Received June 25, 2007; revised Aug. 21, 2007; accepted Sept. 12, 2007.

This work was supported by National Institutes of Health Grants NS049109 (P.F.M.) and MH064056 (Silvio Conte Center for Neuroscience of Mental Disorders), the Pew Charitable Trust (F.P.), March of Dimes (F.P.), and National Institute of Neurological Disorders and Stroke Center Grant P30NS0445892 to the University of North Carolina Neuroscience Center for support of the Confocal and Hybridization Facilities. L.E.-B. was supported by the Spanish Ministry of Education and Science. Dr. David Ginty is gratefully acknowledged for Npn1 antibodies. We thank Dr. Alda Tufro for providing the Semaphorin 3A probe, Dr. Amy Wiencken-Barger for assistance with cytochrome oxidase staining, and Dr. Robert Bagnell (Microscopy Services Laboratory, University of North Carolina, Chapel Hill) for assistance with confocal microscopy.

Correspondence should be addressed to Patricia F. Maness at the above address. E-mail: srclab@med.unc.edu. D0I:10.1523/JNEUROSCI.2888-07.2007

Copyright $\odot 2007$ Society for Neuroscience $\quad$ 0270-6474/07/2713667-13\$15.00/0
}

and the dorsal telencephalon [DTe; FGF8 (Shimogori and Grove, 2005); Emx2 (Hamasaki et al., 2004); CoupTFI (Liu et al., 2000)]. The VTe has emerged as an important intermediate target for initial projection and routing of thalamic axons (Dufour et al., 2003; Lopez-Bendito et al., 2006; Bonnin et al., 2007). At embryonic day 15 (E15)-E16, thalamic axons reach the subplate and wait (Ghosh et al., 1990) until cortical cues, such as neurotrophin-3 (Ma et al., 2002), induce axons to invade the cortex. The initially diffuse projection of axons within each cortical area is refined to layer IV by activity-dependent and independent mechanisms (Katz and Crowley, 2002; Cang et al., 2005; Torii and Levitt, 2005).

Axons from motor nuclei are sorted in the VTe based on complementary gradients of ephrinA (EphA) ligands and EphA receptors (Dufour et al., 2003). However, axons from somatosensory and visual thalamic nuclei maintain correct topography in ephrinA5/EphA4 double knock-out mice, suggesting that other guidance cues direct the growth of these axons toward posterior cortical areas. CHL1 might participate in topographic guidance of these axons, as it is expressed in the dorsal thalamus and the posterior neocortex during thalamocortical projection (Liu et al., 2000; Demyanenko et al., 2004). Sema3A, a secreted sempahorin, is also a candidate axon guidance cue, as it is expressed along the pathway of projecting thalamocortical axons (Skaliora et al., 1998; Tamamaki et al., 2003), and induces collapse of thalamic growth cones in vitro (Bagnard et al., 2001). A link between CHL1 and the Sema3A receptor, neuropilin 1 (Npn1), is plausible based 
on the association of $\mathrm{L} 1$ and $\mathrm{NrCAM}$ with neuropilins (Castellani et al., 2000; Falk et al., 2005).

Here, we show that loss of CHL1 causes somatosensory thalamic axons to lose topography in the VTe and misproject to the visual cortex. In Npn1 $1^{\text {Sema- }--}$ mice, which are unresponsive to Sema3A (Gu et al., 2003), thalamic axons misproject similarly within the $\mathrm{VTe}$, consistent with loss of repellent guidance to the high caudal Sema3A gradient. Furthermore, CHL1 associated with Npn1 and was required for Sema3A-induced thalamic growth cone collapse. Thus, the studies presented here reveal a novel cooperation between CHL1 and Npn1, important for guidance of thalamocortical axons in the VTe, ensuring proper targeting to the somatosensory cortex.

\section{Materials and Methods}

Mice. CHL1 heterozygous mutant mice on a C57BL/6 background (Montag-Sallaz et al., 2002) were intercrossed to obtain CHL1 homozygous null mutants and WT littermates. E0.5 was defined as the plug date and postnatal day $0(\mathrm{PO})$ as day of birth. WT and $\mathrm{CHL}^{-}$mice were intercrossed with enhanced green fluorescent protein (EGFP) transgenic mice in which EGFP is expressed from the chicken $\beta$-actin promoter and a cytomegalovirus (CMV) enhancer (Okabe et al., 1997), to carry out the coculture experiments. Animal care and treatment were in accordance with guidelines provided by the University of North Carolina Institutional Animal Care and Use Committee.

Immunostaining and histology. CHL1 rabbit polyclonal antibody 12146 was raised against recombinant CHL1 fused to the Fc portion of human IgG, and affinity purified, as described previously (Chen et al., 1999). The antibody was specific for CHL1, shown by Western blotting in the mouse forebrain from E13-P15 and adult mice (Hillenbrand et al., 1999). In addition, commercially available CHL1 antibody was used (R\&D Systems, Minneapolis, MN; 1:200) with similar results. Other antibodies used were rabbit polyclonal anti-GFP (Invitrogen, Eugene, OR; 1:1000), rabbit polyclonal anti-Npn1 (gift from Dr. David Ginty, Johns Hopkins University, Baltimore, MD, or from Calbiochem, La Jolla, CA; 1:70), and rat polyclonal anti-L1 (Abcam, Cambridge, UK; 1:50). Whole mounts were permeabilized at $4^{\circ} \mathrm{C}$ overnight using $5 \%$ normal goat serum, $3 \%$ bovine serum albumin, and $0.3 \%$ Triton X-100 in $0.1 \mathrm{M}$ PBS. The sections were then incubated in primary antibody at room temperature during the day and at $4^{\circ} \mathrm{C}$ overnight. After $24 \mathrm{~h}$ of washing with 0.1 M PBS, the sections were incubated all day at room temperature and overnight at $4^{\circ} \mathrm{C}$ in fluorescein isothiocyanate (FITC)- or tetramethylrhodamine isothiocyanate (TRITC)-conjugated secondary antibodies. For histology experiments, wild-type (WT) and CHL1 ${ }^{-}$littermates were anesthetized and perfused and brains were processed for cytochrome oxidase(Boyd and Matsubara, 1996) or Nissl (Demyanenko et al., 1999).

In situ hybridization. cDNA encoding the extracellular region of mouse CHL1 was subcloned into psBluescript $\mathrm{KS}(-)$ and sense and antisense probes were generated by restriction digest (amino acids 1-1083 from GenBank accession number NM_007697), as described previously (Villegas and Tufro, 2002). Brains from WT embryos (E14.5) were immersion fixed in 4\% PFA overnight and cryoprotected in sucrose before sectioning (horizontally or sagittally). In situ hybridization was performed as described using digoxigenin-labeled probes (Colbert et al., 1995).

In vivo axon tracing. Retrograde axon tracing was performed by focal injection of $1,1^{\prime}$, di-octadecyl-3,3,3'3'-tetramethylindocarbocyanine perchlorate (DiI) and 4-4-dihexadecyl aminostyryl $N$-methylpyridinium iodide (DiA) (Invitrogen) solutions (5\% in ethanol) in two distinct cortical areas of living mice anesthetized by hypothermia. Injections were made with capillary micropipettes connected to a Picospritzer II. Mice were killed $2 \mathrm{~d}$ later and fixed by transcardial perfusion. Forebrains were vibratome sectioned in the coronal plane $(100 \mu \mathrm{m})$. Injection sites were monitored microscopically and only those injections restricted to the neocortex, without entering the white matter were further analyzed. The exact locations and positions of the injection sites and the position of thalamic nuclei were identified using bisbenzimide nuclear staining and comparison to atlas coordinates.
For anterograde tracing, WT, $\mathrm{CHL}_{1}{ }^{-}$, and $\mathrm{Npn} 1^{\text {Sema-/- }}$ embryonic brains were fixed in $4 \%$ PFA overnight at $4^{\circ} \mathrm{C}$. After hemidissection, DiA or DiI crystals were inserted into the dorsal thalamus (DT). After diffusion for 2-4 weeks at room temperature, the brains were coronally vibratome sectioned $(100 \mu \mathrm{m})$. Sections were mounted in gel mount containing anti-fading agents (Biomedia, New York, NY) and imaged using epifluorescence microscopy. The size and position of the crystals with respect to the thalamic eminence reference point were verified microscopically. Acceptable injections were within $300 \mu \mathrm{m}$ of the thalamic eminence (for rostral labeling) or $100 \mu \mathrm{m}$ [for ventrobasal (VB) labeling].

The data were analyzed and graphed as reported previously (Dufour et al., 2003) with the $x$-axis (normalized section number) depicting the relative position of sections along the rostrocaudal axis of the VTe with respect to a common reference point $(0 \mu \mathrm{m})$, corresponding to the first section of the thalamic eminence where axons leave the diencephalon and enter the VTe. Because of slight differences in total number of sections among hemispheres, for each genotype section numbers were normalized with respect to the distance from the thalamic eminence $(0 \mu \mathrm{m})$ to the far caudal or rostral section of the hemisphere. The $y$-axis (frequency) represented the percentage of sections among all hemispheres where labeled axons were observed. The section number with the highest frequency along the rostrocaudal axis for each genotype was set at $100 \%$ to facilitate comparison. Individual points along the axon distribution of different genotypes were compared using the $F$ test. The degree of freedom for the numerator (mean variance between samples) and degree of freedom for the denominator (mean variance within a given condition) were used to calculate the $F$ ratio. The $F$ ratio was compared with the critical value associated with the degrees of freedom in the $F$ distribution table. If the calculated $F$ ratio was larger than the critical value associated with $\alpha=0.05$, the null hypothesis was rejected and a significant difference was concluded.

In vitro organotypic assays. WT or $\mathrm{CHL}^{-}{ }^{-}$transgenic embryos ubiquitously expressing EGFP were killed at E14.5. To examine corticofugal axon outgrowth, the DTe from EGFP expressing WT and CHL1 ${ }^{-}$embryos was cocultured with explants of VTe and DT from unlabeled WT embryos. Organotypic cocultures were arranged using an air-interface protocol (Polleux and Ghosh, 2002) and maintained in a 5\% $\mathrm{CO}_{2}-$ humidified incubator for $3 \mathrm{~d}$ in vitro. The EGFP signal was enhanced by immunostaining with antibodies against EGFP and imaged using a Leica (Oberkochen, Germany) DM IRE2 confocal microscope. Optical density (OD) of the EGFP immunofluorescent signal was measured in ImageJ using the Radial Sums analysis of the Oval Profile plug-in (http:// rsb.info.nih.gov/ij/plugins/oval-profile.html). Individual OD measurements were normalized to the maximal and minimal OD value in each experiment. OD measurements were analyzed using Prism 4.0 for Macintosh. A one-way ANOVA with a Tukey's multiple-comparison post hoc test was used to describe the global difference between each coculture condition.

Cocapping assay. COS-7 cells were cotransfected with pCos-BMNNpn1 and pcDNA3-CHL1 or pcDNA3-CHL1 $1_{\mathrm{L} 115 \mathrm{~V}}$ mutant. The cells were then dissociated with 5 mm EDTA in HBSS, washed with $10 \%$ fetal bovine serum in DMEM, and resuspended in ice-cold DMEM. To cap surface Npn1, the cells $(30,000$ cells $/ 100 \mu \mathrm{l})$ were incubated with antiNpn 1 rabbit polyclonal antibody $(40 \mu \mathrm{g} / \mathrm{ml})$ at $4^{\circ} \mathrm{C}$ for $20 \mathrm{~min}$. To cap surface CHL1, cells were incubated with anti-CHL1 goat polyclonal antibody $(40 \mu \mathrm{g} / \mathrm{ml})$. The cells were washed in ice-cold DMEM, resuspended in DMEM containing $10 \mu \mathrm{g} / \mathrm{ml}$ of mouse anti-rabbit IgG to cluster Npn1 or mouse anti-goat IgG to cluster CHL1 and incubated for 20 min on ice. After washing with ice-cold DMEM, cells were resuspended in $10 \%$ fetal bovine serum in DMEM and plated onto fibronectin coated MatTek (Ashland, MD) dishes. Cells were incubated for $1 \mathrm{~h}$ at $37^{\circ} \mathrm{C}$ and then fixed with $4 \%$ PFA for $15 \mathrm{~min}$. After washing, cells were blocked in $10 \%$ donkey serum for $1 \mathrm{~h}$ at room temperature. To label CHL1, the cells were incubated with anti-CHL1 goat polyclonal antibody ( $20 \mu \mathrm{g} / \mathrm{ml}$ in blocking buffer) for $2 \mathrm{~h}$ at room temperature and washed with PBS. To label Npn1, cells were incubated with anti-Npn1 rabbit polyclonal antibody $(20 \mu \mathrm{g} / \mathrm{ml})$. Npn1 and CHL1 were detected by incubating the cells with FITC and TRITC-conjugated donkey anti-rabbit 
and donkey anti-goat secondary antibodies, respectively (diluted 1:100 in blocking buffer) for $1 \mathrm{~h}$ at room temperature. Cells were treated with nonimmune IgG antibodies to ensure no cross-reactivity of the secondary antibodies. Finally, the cells were washed, mounted in Vectashield, and imaged using an Olympus (Tokyo, Japan) FV500 laser confocal microscope.

Coimmunoprecipitation. COS-7 cells were cotransfected with CHL1 or $\mathrm{CHL}_{\mathrm{L} 115 \mathrm{~V}}$ and myc-tagged Npn1 using Lipofectamine 2000. After $2 \mathrm{~d}$, cells were lysed on ice with immunoprecipitation buffer $(20 \mathrm{~mm}$ Tris $\mathrm{HCl}, 150 \mathrm{~mm} \mathrm{NaCl}, 5 \mathrm{~mm} \mathrm{Na}^{+}$EDTA, $2 \mathrm{~mm} \mathrm{Na}^{+}$EGTA, $10 \mathrm{~mm}$ sodium fluoride, $1 \mathrm{~mm}$ sodium pervanadate, $1 \mathrm{~mm}$ phenlymethylsulfonyl fluoride, $1 \%$ Triton $\mathrm{X}-100$ ) including protease inhibitors. Whole brains were isolated from E16.5 WT embryos and lysed in complete radioimmunoprecipitation assay buffer $(20 \mathrm{~mm}$ Tris $\mathrm{HCl}, 0.15 \mathrm{M} \mathrm{NaCl}, 5 \mathrm{~mm}$ Na plus EDTA, 1 mm Na plus EGTA, 1\% NP-40, 1\% Na-deoxycholate, 0.1\% SDS, $0.2 \mathrm{~mm}$ sodium orthovadandate, $10 \mathrm{~mm}$ sodium fluoride) including protease inhibitors. The lysates were incubated for $10 \mathrm{~min}$ at $4^{\circ} \mathrm{C}$ and clarified by centrifugation for $10 \mathrm{~min}$. After preclearing with mouse or rabbit IgG for $30 \mathrm{~min}$ at $4^{\circ} \mathrm{C}$, samples were immunoprecipitated with mouse anti-myc $(10 \mu \mathrm{g})$ or rabbit anit-Npn1 $(1 \mu \mathrm{g} / \mathrm{ml}$; Millipore, Temecula, CA) antibodies for $1 \mathrm{~h}$ at $4^{\circ} \mathrm{C}$. The beads were then washed and the precipitates were analyzed by immunoblotting with anti-CHL1 goat polyclonal antibody (1:1000) and an HRP-conjugated bovine anti-goat IgG antibody using enhanced chemiluminescent detection (Pierce, Rockford, IL).

Growth cone collapse assay. CHL1 ${ }^{-}$thalamic embryonic (E14.5) neurons were obtained by isolating the thalamus and dissociating the cells in $3 \mathrm{ml}$ of ice-cold HBSS. Cells were further dissociated by trituration with a $10 \mathrm{ml}$ pipette followed by a wide bore Pasteur pipette and immediately cotransfected with pMax-GFP $(0.9 \mu \mathrm{g})$ and pcDNA3-CHL1wt, pcDNA3-CHL1 $1_{\mathrm{L} 115 \mathrm{~V}}$, or empty pcDNA3 $(2.3 \mu \mathrm{g})$ by electroporation using an Amaxa (Gaithersburg, MD) nucleofector device and mouse neuron nucleofector kit (Amaxa). Briefly, $5 \times 10^{6}$ cells were resuspended in transfection buffer and program $\mathrm{O}-05$ was used to electroporate the DNA (1:1 molar ratio) into the cells. Cells were allowed to recover in RPMI medium (Invitrogen) for $5 \mathrm{~min}$, and then plated on fibronectincoated MatTek dishes in 10\% fetal bovine serum and DMEM. The day after plating, the media was changed to Neurobasal media containing B27 supplement and glutamate $(25 \mu \mathrm{M})$ to select for neurons. After $48 \mathrm{~h}$ of incubation, cells were treated with either Fc protein fused to alkaline phosphatase $(\mathrm{Fc}-\mathrm{AP})$ or Sema3A protein fused to alkaline phosphatase (Sema3A-AP) fusion proteins $(30 \mathrm{~nm})$ for $30 \mathrm{~min}$. Fc-AP and Sema3A-AP were prepared by transfecting human embryonic kidney 293T (HEK293T) cells using Lipofectamine 2000. After 2 d, media was collected and the concentration was determined as described by Flanagan and Leder (1990). Cells were then fixed with 4\% PFA and permeabilized with $0.2 \%$ Triton X-100 for $5 \mathrm{~min}$. After washing, cells were treated with rhodamine-conjugated phalloidin (Invitrogen; 1:40) for $30 \mathrm{~min}$ at room temperature to visualize actin within the growth cone. Only cells expressing GFP were included in the analysis. After $48 \mathrm{~h}$, the rate of transfection was determined to be $\sim 55 \%$. Cells were mounted in Vectashield and growth cone morphology was observed using confocal microscopy.

For explant studies, WT and CHL1 ${ }^{-}$embryonic (E14.5) brains were vibratome sectioned $(300 \mu \mathrm{m})$ and thalamic regions were obtained by microdissection in ice-cold HBSS. Explants were plated on fibronectincoated Mat-Tek dishes using a plasma clot $(20 \mu \mathrm{l}$ of bovine thrombin with $20 \mu \mathrm{l}$ of chicken plasma; Sigma, St. Louis, MO) to ensure adherence of the explant. The explants were cultured and growth cone morphology was analyzed as described above.

\section{Results}

\section{CHL1 is expressed in the thalamocortical pathway}

Expression of CHL1 was analyzed in mouse embryos at E14.5, during projection of thalamic axons across the VTe, and at E16.5, when thalamic axons have reached the DTe (Seibt et al., 2003) by immunofluorescence staining. CHL1 antibodies have been shown to be specific for CHL1 in the mouse forebrain (E13-P15) [\#2198 (Hillenbrand et al., 1999)], hippocampus [\#3681 (Ni- konenko, 2006)], and primary neuronal cultures [\#3682 (Leshchyns'ka, 2006)]. CHL1 antibodies do not cross react with L1 family members as shown in Figure 6, where Western blotting of E16.5 mouse brain indicates recognition of only the CHL1 doublet comprised of unprocessed and mature forms $(180,165$ $\mathrm{kDa})$ and not proteins of the size of $\operatorname{NrCAM}(144 \mathrm{kDa})$ or neurofascin $(150 \mathrm{kDa})$. In addition, CHL1, and not $\mathrm{L} 1$, is recognized by the CHL1 antibodies on Western blots of HEK293 cells transfected with L1 or CHL1 cDNA. At E14.5, CHL1 immunoreactivity was robust within the dorsal thalamus (DT) and internal capsule (IC) of the VTe, as well as in the cortical intermediate zone (IZ), cortical plate (CP), and marginal zone (MZ), as shown in a coronal section midway along the rostrocaudal axis (Fig. 1A). A similar pattern of CHL1 expression was observed at E16.5 in the DT, IC, and neocortex (Fig. $1 B, C$ ). No staining was observed with nonimmune IgG (Fig. 1C). In situ hybridization showed expression of CHL1 mRNA within the DT at E14.5. Examination of serial horizontal sections through the DT indicated that CHL1 was expressed in a high ventral to low dorsal gradient (Fig. 1D), corresponding to the approximate location of the VB nuclei (Altman and Bayer, 1995). CHL1 transcripts were also evident in the $\mathrm{CP}$ and IZ, most likely corresponding to migrating neurons, but not in the lateral (LGE) or medial ganglionic eminence (MGE) (Fig. $1 E$ ). To better define the localization of CHL1 protein to thalamocortical and/or corticofugal axons, explants from the DT were isolated from transgenic mouse embryos (E14.5) expressing EGFP from the chicken $\beta$-actin promoter (Okabe et al., 1997), cocultured with a whole mount of isochronic telencephalic vesicle from unlabeled embryos (Dufour et al., 2003; Seibt et al., 2003). CHL1 immunofluorescence was evident on EGFPexpressing thalamic axons, where it localized to growth cones and axon shafts (Fig. $1 F, G$ ). CHL1 staining was also apparent on non-EGFP expressing axons derived from the telencephalon (Fig. $1 F$, red fibers). These results indicated that CHL1 was localized on both embryonic thalamocortical and corticofugal axons during thalamocortical projection.

\section{CHL1 is required for interareal targeting of thalamocortical projections to the somatosensory cortex}

Retrograde axon tracing of thalamocortical projections was performed in WT and homozygous CHL1 mutant mice at P5, when thalamocortical targeting is established (Agmon et al., 1995). WT and $\mathrm{CHL1}^{-}$littermates were dually injected with DiI into the primary visual cortex (V1) and DiA into the primary somatosensory cortex (S1) (Fig. 2A). The accuracy of all injections was monitored for correct rostral-caudal and dorsal-ventral positioning by epifluorescence microscopy. In vivo, DiI is almost exclusively taken up by thalamic axons and transported retrogradely via active transport, labeling cell bodies in the thalamus (Fig. 2E, inset). In all WT mice, DiI injection (red) into V1 retrogradely labeled the lateral geniculate nucleus (LGN) of the dorsal thalamus, and DiA injection (green) into S1 retrogradely labeled the ventroposterior lateral (VPL) and ventroposterior medial nuclei (VPM) of the VB (Fig. $2 B, C, G$ ). In $\mathrm{CHL}^{-}{ }^{-}$mice, injection of DiI into $\mathrm{V} 1$ resulted in unexpected labeling (red) of neuronal cell bodies in VB nuclei, in addition to expected labeling of the LGN (Fig. 2D,E). Injection of DiA into S1 resulted in appropriate labeling of the VPL and VPM nuclei in all CHL1 mutants. Mistargeting of VB axons to the visual cortex was almost fully penetrant (16 of 18 mutant hemispheres), whereas none of the 13 WT hemispheres analyzed displayed these defects. Chi-square analysis showed that this defect was significant for CHL1-mutants $\left(\chi_{0.005}^{2}=13.72\right)$. 
Previous studies have shown that for proper cortical targeting, thalamic axons must encounter appropriate subplate and cortical plate layers, within which axons interact with positional cues necessary for proper guidance and targeting (Ghosh and Shatz, 1993; Shimogori and Grove, 2005). CHL1 is expressed in subplate neurons (Liu et al., 2000), however, CHL1 deficiency did not affect the generation or laminar positioning of these cells, as determined either by staining for Tbr1, a marker of subplate/layer VI neurons at P0 (data not shown) or by bromodeoxyuridine labeling of these cells at E11.5 followed by analysis at P0 (Demyanenko et al., 2004). Mistargeting of somatosensory thalamic axons in $\mathrm{CHL}^{-}$mice did not obviously affect the number or positioning of barrels in the somatosensory cortex seen by Nissl (Fig. $2 J, K$ ) or cytochrome oxidase staining (Fig. $2 L, M$ ), although subtle alterations in barrel positioning may not have been detected.

To rule out the possibility that the defects observed in thalamic axon targeting were secondary because of defective corticothalamic projections, corticofugal axon outgrowth was examined using an organotypic coculture assay, as previously described (Seibt et al., 2003). Whole mounts of DTe where isolated from embryos expressing EGFP (E14.5), from the chicken $\beta$-actin promoter and CMV enhancer (Okabe et al., 1997). WT DTe explants were cocultured with unlabeled WT explants containing the VTe and DT (E14.5). Corticofugal axons of WT embryos displayed the expected topography and uniform outgrowth across the extent of the telencephalon (supplemental Fig. 1, available at www.jneurosci.org as supplemental material). Labeled DTe explants from $\mathrm{CHL}^{-}{ }^{-}$embryos were also cocultured with unlabeled WT explants containing the VTe and DT. Corticofugal axon outgrowth was unaltered by the loss of CHL1 from the DTe. The data were quantified by measuring optical density of the EGFP fluorescent signal, which correlates with total corticofugal axon outgrowth. There was no statistical difference in overall outgrowth resulting from loss of CHL1 (supplemental Fig. 1, available at www.jneurosci.org as supplemental material). Thus, misguidance of $\mathrm{CHL}^{-}{ }^{-} \mathrm{VB}$ axons was unlikely caused by impaired corticofugal axon outgrowth in the VTe.

To determine whether thalamic axons projected aberrantly to the primary motor cortex (M1), DiI was injected into the M1 area of WT and CHL1 ${ }^{-}$littermates at P5. In all WT $(n=8)$ and $\mathrm{CHL}^{-}(n=6)$ mice, DiI (red) injections resulted in appropriate labeling of the ventrolateral nucleus (VL), a motor thalamic nucleus (Fig. $2 F, H$ ). This result indicated that motor thalamic axons were not dependent on CHL1 for correct mapping to M1,
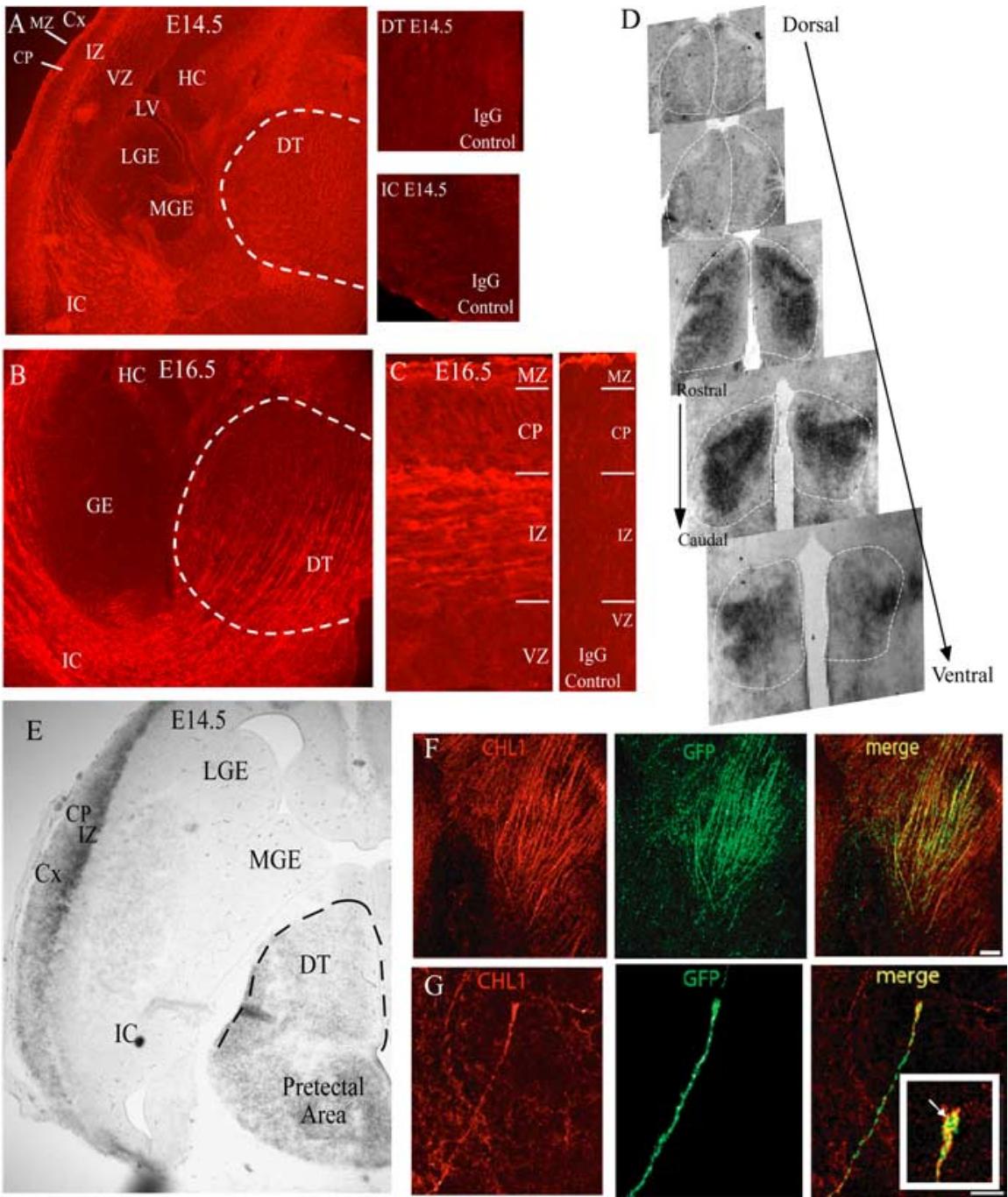

Figure 1. CHL1 is expressed in the developing thalamocortical pathway. $\boldsymbol{A}$, Immunofluorescence staining for CHL1 in a midcoronal section (to best observe the entire thalamocortical pathway) of WT brain during projection of thalamic axons to the observed with nonimmune lg G. B, Immunofluorescence staining for CHL1 in a midcoronal section of E16.5 WT brain visualized by confocal microscopy. CHL1 protein is prominent in the DT and IC, and is also present in the hippocampus (HC). C, CHL1 localization in the caudal cortex of E16.5 WT brain visualized by confocal microscopy. CHL1 is most prominent in the IZ and MZ, and to a lesser extent in the CP. No staining was observed with nonimmune lgG. D, In situ hybridization for CHL1 mRNA in WT embryos (E14.5) in serial horizontal sections (to best observe the dorsal thalamus). Sections are $20 \mu \mathrm{m}$ thick and representative of the entire dorsoventral axis of the dorsal thalamus. CHL1 was expressed in a low dorsal to high ventral gradient throughout the dorsal thalamus. $\boldsymbol{E}$, CHL1 transcripts were also evident in the pretectal area and the cortical IZ and CP, but not the LGE or MGE. $\boldsymbol{F}, \boldsymbol{G}$ EGFP-labeled WT thalamic explants were cocultured with unlabeled WT telencephalic whole mounts (E14.5) and immunostained for CHL1 (red) and GFP (green). F, Thalamocortical axons (green) show localization with CHL1 (yellow in merge). Corticofugal axons also show CHL1 localization (red in merge). Scale bar, $100 \mu \mathrm{m}$. G, Single TC axon expressing CHL1 shown by localization of EGFP (green) with CHL1 (red) along the axon shaft and within the growth cone (yellow in merge). Scale bar, $50 \mu \mathrm{m}$.

and that axons from nonmotor thalamic nuclei do not target the motor cortex.

In summary, axon tracing experiments revealed that a contingent of thalamic axons from VB nuclei projected inappropriately to targets in the visual cortex in $\mathrm{CHL}^{-}$mice, whereas motor and visual thalamic axons targeted correct cortical areas (Fig. 2I).

\section{CHL1 is required for guidance of thalamic axons within the telencephalon}

To determine whether CHL1 influences guidance of thalamic axons in the VTe, anterograde axon tracing was performed in WT and $\mathrm{CHL1}^{-}{ }^{-}$embryos at E15.5, when thalamic axons have mi- 

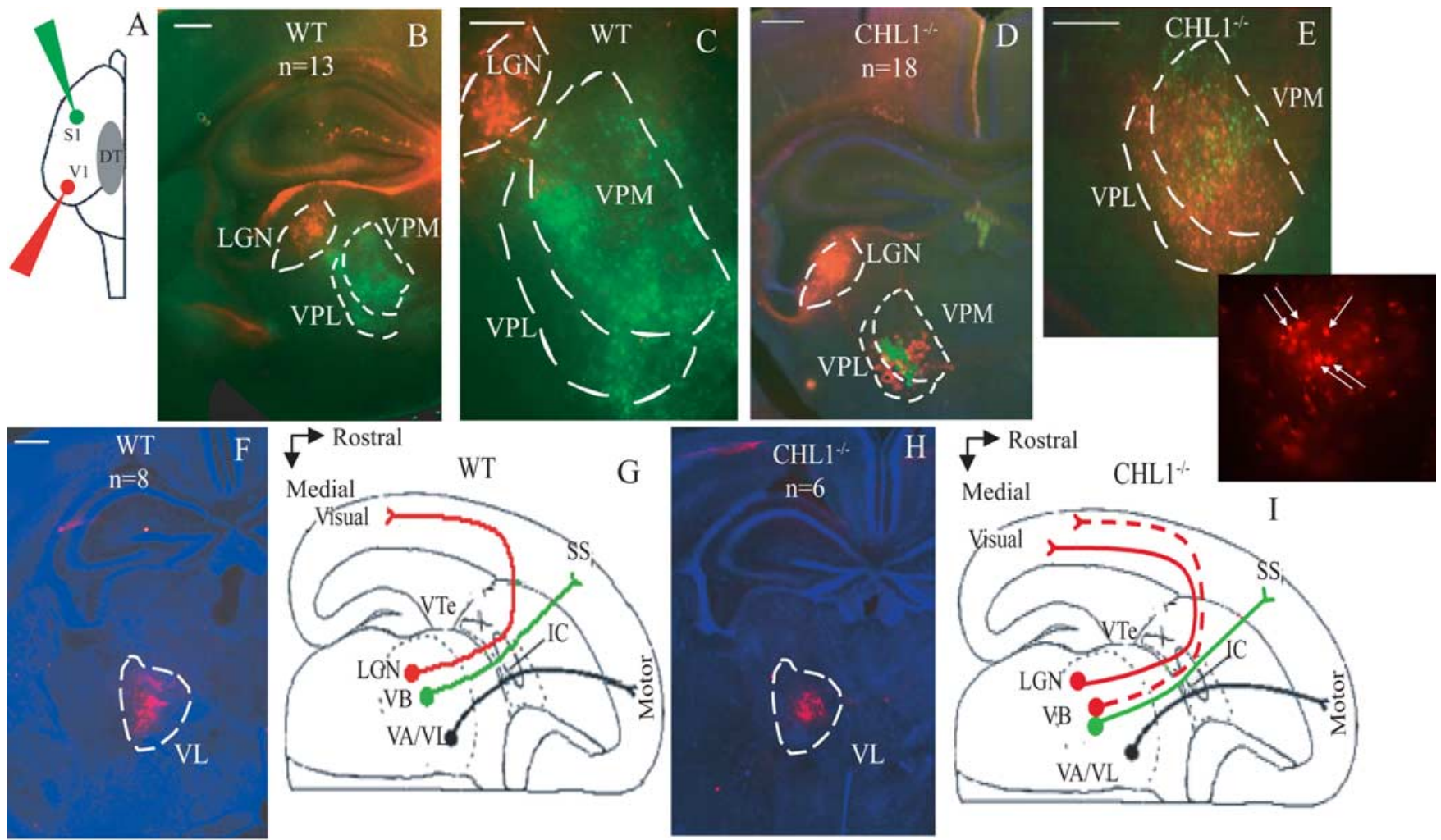

$\mathrm{CHL1}^{\text {H. }}$
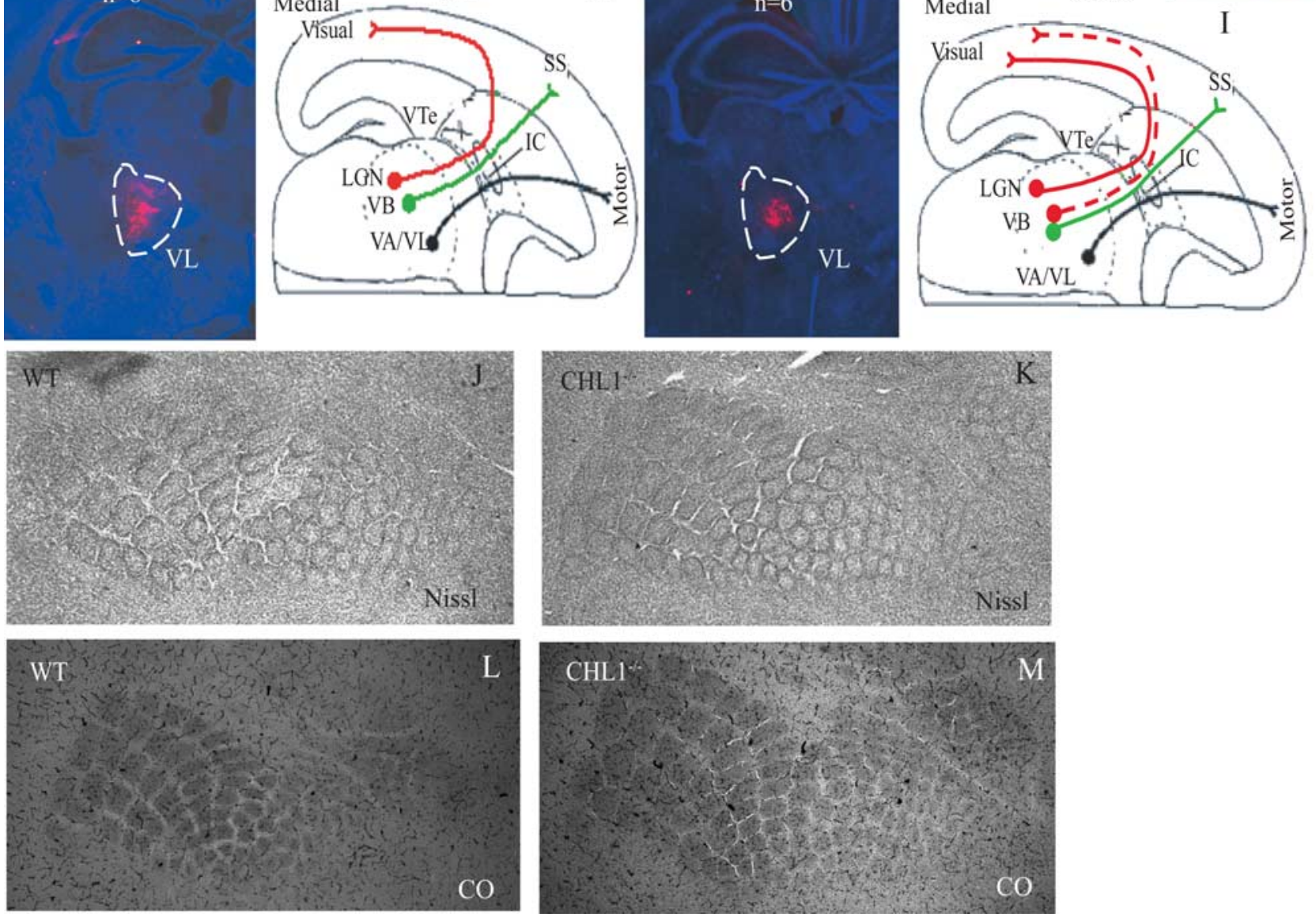

Figure 2. Projection of somatosensory thalamic axons is caudally shifted to the visual cortex in CHL1- mice. A, Scheme illustrating location of injections of Dil (visual cortex) and DiA (somatosensory cortex) of P5 mice. Appropriate location and position of injections were confirmed using fluorescent microscopy. $B, C$, Retrograde labeling of thalamocortical axons of WT mice ( $n=$ 13). Scale bars: $\boldsymbol{B}, 100 \mu \mathrm{m} ; \boldsymbol{C}, 50 \mu \mathrm{m}$. Expected projection patterns of Dil labeling (red) in the LGN and DiA labeling (green) in the VB (VPM and VPL) are shown. $\boldsymbol{D}, \boldsymbol{E}$, Retrograde labeling of thalamocortical axons in CHL1- mice $(n=18)$. Scale bars: $\boldsymbol{D}, 100 \mu \mathrm{m} ; \boldsymbol{E}, 50 \mu \mathrm{m}$. Appropriate DiA labeling (green) in the VPL and VPM was evident. Expected Dil labeling (red) in the LGN, as well as unexpected labeling of the VPL and VPM was observed. Inset, High-magnification image of cell bodies in the dorsal thalamus retrogradely labeled by Dil. $F$, Retrograde labeling of thalamocortical axons of WT mice $(n=8)$ injected with Dil in the motor cortex at P5. Dil labeling (red) is present only in the appropriate location of the ventrolateral nucleus. Scale bar, $100 \mu \mathrm{m}$. G, Scheme illustrating the thalamocortical projection pathway of WT mice. Normal TC axons from the LGN project to the visual cortex; axons from the VB complex project to the somatosensory cortex, and axons from the VA/VL project to the motor cortex. $\boldsymbol{H}$, Retrograde labeling with Dil injected in the motor cortex of $\mathrm{CHL1}{ }^{-}$mice $(n=6)$ at P5. Dil labeling (red) is present only in the ventrolateral nucleus. Scale bar, $100 \mu \mathrm{m}$. I, Scheme illustrating the altered thalamocortical topography in CHL1 ${ }^{-}$mice. TC axons from the LGN project appropriately to the visual cortex, whereas axons from the VB complex project appropriately to the somatosensory (SS) cortex and inappropriately to the primary visual cortex (dashed red line). Axons from the VA/VL project appropriately to the motor cortex. $J$, $K$, Niss $\mathbf{s}$ saining of WT and CHL1 ${ }^{-}$adult mice demonstrate the positioning of barrels in layer IV of S1. No differences were observed. L, M, Cytochrome oxidase staining of WT and CHL1 ${ }^{-}$littermates at P5 to observe the barrels in layer IV of S1. Number and positioning of barrels was not affected by loss of CHL1. VA, Ventroanterior nucleus.

grated across the VTe and reached the DTe. At this stage axons from the rostral dorsal thalamus (DTR) preferentially grow through the rostral domain of the VTe, although central dorsal thalamic axons, located midway on the rostral-caudal axis of the thalamus, occupy more medial territories and caudal axons, the caudal VTe (Seibt et al., 2003). DiI was injected into the rostral third of the DT, and thalamic axon projections were analyzed (Fig. 3A). DTR axons of CHL1 mutants projected normally 
across the VTe and were visible at the same level within WT and $\mathrm{CHL}^{-}$embryos (Fig. $3 B, C$ ). Analysis of DTR axons throughout the rostrocaudal extent of the VTe confirmed a mostly similar distribution for WT and CHL1 mutant populations (Fig. 3D). Quantification of the mean distance of the rostral-most rostral thalamic axons (measured from the first section where rostral axons were visible to the thalamic eminence at reference point 0 ) showed no significant differences in WT $(1.2 \pm 0.14 \mathrm{~mm})$ and CHL1 ${ }^{-}$embryos $(1.17 \pm 0.18 \mathrm{~mm}$; Mann-Whitney test, two-tailed $M=58.5 ; \alpha=0.05)$.

In contrast, axons from the VB nuclei of $\mathrm{CHL1}^{-}{ }^{-}$embryos were shifted caudally within the VTe. For these experiments, DiI was injected deep into the central third of the DT of WT and $\mathrm{CHL1}^{-}$littermates (E15.5) (Fig. 3E). No labeled axons were visible in WT VTe in sections $\sim 400 \mu \mathrm{m}$ caudal to the thalamic eminence (Fig. $3 F$ ), whereas DiI labeled fibers were consistently observed in the VTe of CHL1 ${ }^{-}$mice at an equivalent level (Fig. 3G). DiI labeled fibers from the VB were observed in more rostral levels of the WT VTe (Fig. $3 H$ ). Analysis of the distribution of labeled VB axons in the VTe confirmed that CHL1 ${ }^{-}$ axons were shifted caudally (Fig. 3I). Quantification of the mean distance of the caudal-most caudal thalamic axons to the thalamic eminence of VB thalamic axons of $\mathrm{CHL}^{-}{ }^{-}$embryos $(0.49 \pm 0.08 \mathrm{~mm})$ compared with WT $(0.150 \pm 0.05 \mathrm{~mm})$ indicated a significant difference (MannWhitney, two-tailed $M=50.5 ; \alpha=0.1$ ). Thus, these results support a role for CHL1 in guidance of this population of thalamic axons at the intermediate target.

In vitro studies have indicated a role for Sema3A in homotypic fasciculation of thalamic and cortical axons that may be important for maintaining their segregation during projection to the neocortex (Bagnard et al., 2001). To determine whether CHL1 was required for fasciculation within the VTe, DiI was injected in the cortex and DiA into the DT of WT and $\mathrm{CHL}^{-}$embryos (E16.5). No defects in fasciculation or segregation of thalamic and cortical axons within the VTe were observed (supplemental Fig. 2, available at www.jneurosci.org as supplemental material). Segregation within the cortex could not be visualized because of intense labeling of DiI.

\section{CHL1 colocalizes with the Sema3A receptor neuropilin 1}

To investigate whether CHL1 participates in thalamic axon responses to Sema3A, coexpression of CHL1 and Npn1 was investigated by immunofluorescence staining during thalamocortical outgrowth (E14.5), cortical targeting (E16.5), and after the establishment of thalamocortical projections (P5). At both embryonic stages, Npn1 was expressed in the DT and VTe and colocalized

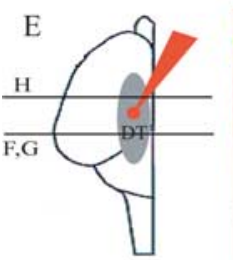

I test).
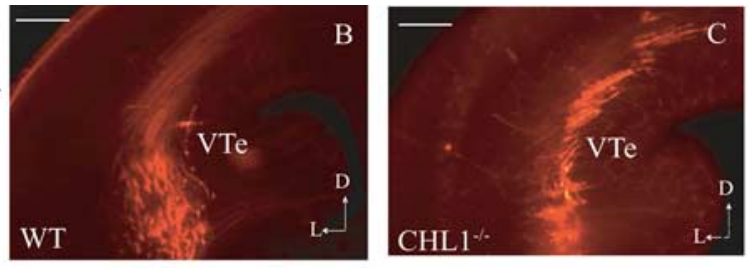

D Analysis of rostral axons (Dil) within the VTe
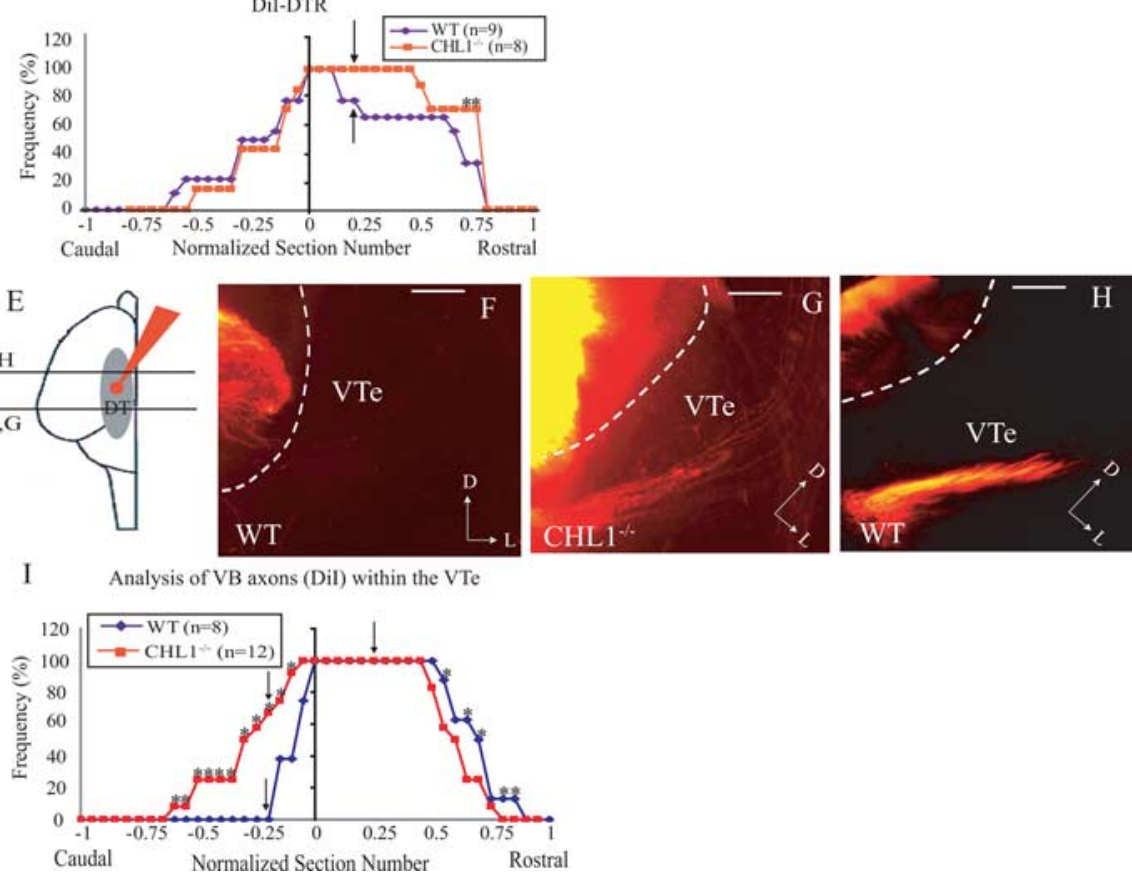

Figure 3. $\mathrm{CHL}{ }^{-}$thalamic axons are altered in the ventral telencephalon at E15.5. $A$, Scheme illustrating placement of Di crystal in rostral dorsal thalamus of mouse embryos. Lines indicates level of sections at $400 \mu \mathrm{m}$ rostral of the thalamic eminence. $\boldsymbol{B}, \boldsymbol{C}$, Anterograde tracing of $(\boldsymbol{B})$ WT $(n=9)$ and $(\boldsymbol{C}) \mathrm{CHL}^{-}(n=8)$ embryos with only rostral (red) axons present in the VTe. Seven of eight mutant hemispheres displayed normal topography. Scale bar, $50 \mu \mathrm{m}$. D, Quantification of the rostrocaudal distribution of rostral thalamic axons within the VTe of WT and CHL1 ${ }^{-}$embryos. The reference point ( 0$)$ corresponds to the first section of the a proportion of total number of hemispheres examined where rostral axons were found was plotted versus the normalized section along the rostrocaudal axis for both WT (blue curve) and $\mathrm{CHL}^{-}{ }^{-}$(red curve) mice. Asterisks indicate significance between third of the dorsal thalamus of mouse embryos. Lines indicate level of sections at $400 \mu \mathrm{m}$ caudal of the thalamic eminence $(\boldsymbol{G}, \boldsymbol{H})$ in eminence in WT VTe rostral (red) thalamic axons were present. 10 of 12 mutant hemispheres displayed aberrant

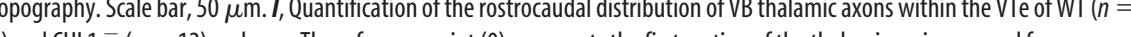
$n=12$ ) embryos. The reference point (0) represents the first section of the thalamic eminence and frequency of 作 $\mathrm{CHL}^{-}$VTe is evident. Asterisks indicate significance between WT and $\mathrm{CHL}{ }^{-}{ }^{-}$distributions at individual points $(p<0.05 ; F$

extensively with CHL1 on fibers (Fig. $4 A, B, D$ ). Coronal sections through ventral regions of the DT, where CHL1 is prominently expressed, are shown here. In the E14.5 cortex, Npn1 was present in the IZ and CP, and colocalized with CHL1 on axons within the IZ (Fig. 4C). At E16.5, thalamocortical axons enter the neocortex and travel within the upper IZ, segregated from corticothalamic axons in the lower IZ (Bagnard et al., 1998). At this stage, Npn1 and CHL1 colocalized in both the upper and lower IZ, suggesting that they may reside on both axonal subsets (Fig. 4E). Npn1 exhibited a nongraded pattern of expression at both stages along the rostrocaudal cortical axis. Npn1 also colocalized with CHL1positive fibers in the dorsal thalamus at P5 (Fig. $4 F$ ), specifically in the $\mathrm{VB}$ complex (Fig. $4 F^{\prime}$ ), suggesting that the receptor for 


\section{E14.5}
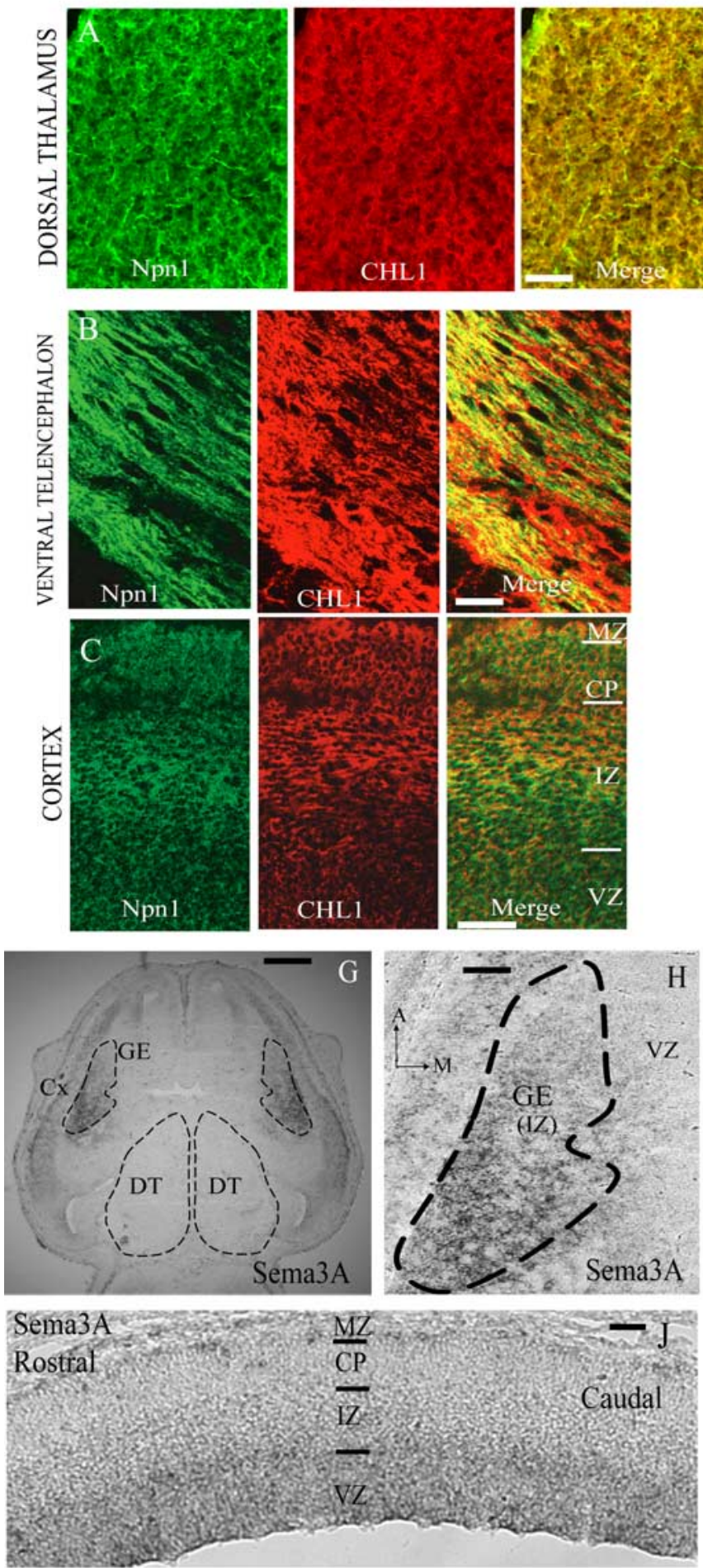

\section{E16.5}
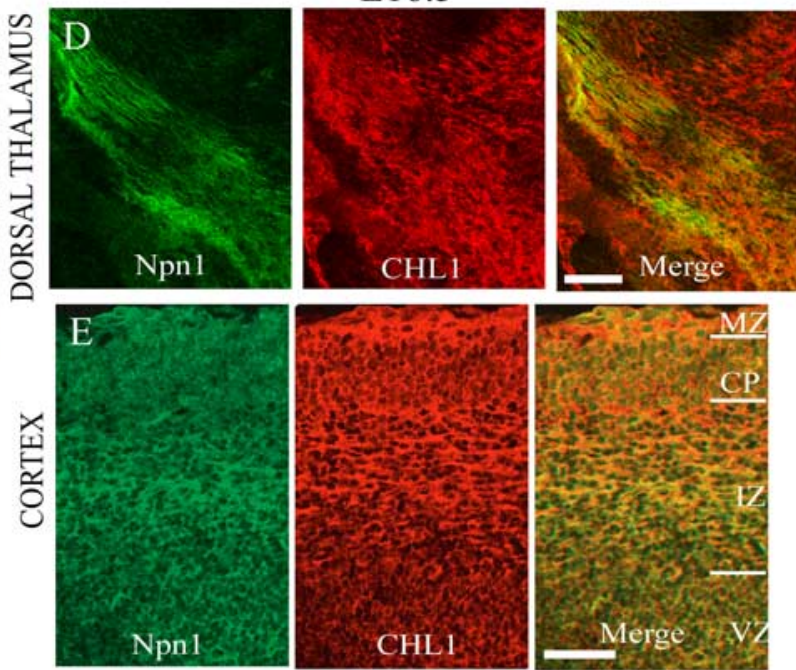

P5
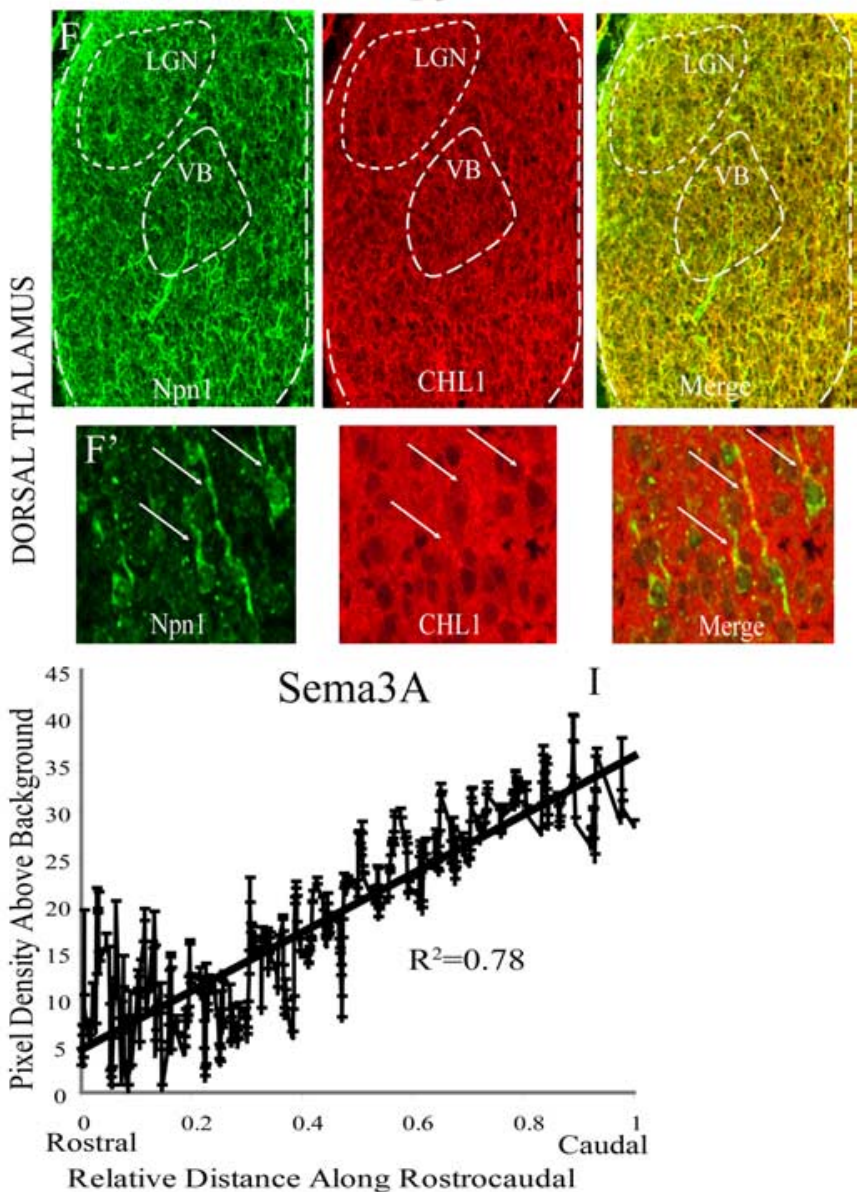

Relative Distance Along Rostrocaudal

Axis of VTe

Figure 4. Expression of CHL1, neuropilin 1, and Sema3A in the embryonic dorsal thalamus and telencephalon. $\boldsymbol{A}-\boldsymbol{C}$, Immunofluorescence staining for Npn1 (green) and CHL1 (red) in coronal sections of WT brain at E14.5 through the dorsal thalamus $(\boldsymbol{A})$, the VTe $(\boldsymbol{B})$, and the cortex $(\boldsymbol{C x})(\boldsymbol{C})$. CHL1 colocalized with Npn1 in fibers of the upper IZ (C) and in axons of the DT and VTe, consistent with the location of thalamocortical fibers. Scale bars: $\boldsymbol{B}, 20 \mu \mathrm{m} ; \boldsymbol{A}, \boldsymbol{C}, 100 \mu \mathrm{m}$. D, E, Npn1 (green) and CHL1 (red) colocalization was observed by immunofluorescence staining at E16.5 in coronal sections through the DT $(\boldsymbol{D})$ and $(x(\boldsymbol{E})$. Fibers in the DT and the upper and lower IZ express both CHL1 and Npn1. The location of these fibers is consistent with the positioning of thalamocortical and corticofugal axons. Scale bars: $\boldsymbol{D}, 20 \mu \mathrm{m} ; \boldsymbol{E}, 100 \mu \mathrm{m}$. $\boldsymbol{F}$, Immunofluorescence staining for Npn1 (green) and CHL1 (red) in coronal sections at P5 through the DT. The merged image shows colocalization of Npn 1 and CHL1 throughout the DT. $\boldsymbol{F}^{\prime}$, High-magnification of fibers within the VB complex of the DT, indicating colocalization of Npn1 and CHL1. G, H, In situ hybridization for Sema3A mRNA in WT embryos at E14.5 in horizontal sections. Sema3A mRNA was evident within the IZ of the ganglionic eminence (GE) in a high-caudal to low-rostral gradient. No expression was observed in the DT (G). Scale bars: $\mathbf{G}, 50 \mu \mathrm{m} ; \boldsymbol{H}, 20 \mu \mathrm{m}$. I, Pixel densities were measured along the rostrocaudal axis of the VTe from serial sections of three embryos using ImageJ Software and normalized to background levels. These data fit a linear regression with an $R^{2}$ value equal to 0.78.J, In situ hybridization for Sema3A in a sagittal section through the neocortex. Sema3A transcripts were robustly expressed in the ventricular zone and marginal zone with little in the IZ. Scale bar, $100 \mu \mathrm{m}$. 
Sema3A may play a role in guiding these axons to their final targets.

In situ hybridization for Sema3A transcripts at E14.5 showed robust expression within the VTe, but not in the dorsal thalamus. Throughout serial horizontal sections, a high-caudal to low-rostral gradient of Sema3A expression was observed in the intermediate zone of the ganglionic eminence within the VTe (Fig. 4G,H). The control sense probe did not generate signals above background levels (data not shown). The gradient of Sema3A expression was quantified by measuring pixel densities along the rostrocaudal axis of the VTe and normalizing these values to background levels. The average pixel density in the caudal VTe was significantly greater than in rostral regions and the data fit a linear regression (Fig. 4I). Thus, Sema3A forms a spatial gradient (high caudal to low rostral) of gene expression in the VTe at E14.5. Sema3A mRNA was also seen in the VZ, and to a lesser extent in the CP, of the neocortex at E14.5, in accord with previous studies (Bagnard et al., 1998; Skaliora et al., 1998; Tamamaki et al., 2003) (Fig. 4J).

\section{Npn1 binding to Sema3A is required for guidance of thalamic axons within the ventral telencephalon}

To establish a role for Npn 1 and Sema3A in thalamocortical axon guidance in vivo, thalamic axons were traced in Npn1 $1^{\text {Sema-l- }}$ mutant mice at E16.5. Npn $1^{\text {Sema-l- }}$ mice express normal levels of Npn1 protein and retain VEGF (vascular endothelial growth factor)-Npn1 signaling, but Sema-Npn1 signaling is abolished and neurons are completely unresponsive to Sema3A (Gu et al., 2003). Because Npn1 null mice die midway through gestation $(\sim$ E10.5-E12.5) (Kitsukawa et al., 1997, 1999), Npn1 $1^{\text {Sema-l- }}$ mice were chosen to study the role of Npn1-Sema signaling on thalamocortical axon guidance. DiI was injected into the rostral third of the DTR from WT and Npn $1^{\text {Sema-l- }}$ littermates and thalamic axon distribution was analyzed (Fig. 5A). DTR axons from Npn $1^{\mathrm{Sema-l-}}$ mutants projected normally across the VTe and were visible at the same level as observed in WT (Fig. $5 B, C)$. Analysis of the distribution of DTR axons across the rostrocaudal extent of the VTe revealed a similar pattern for WT and Npn $1^{\text {Sema-l- }}$ mutant populations (Fig. 5D). Quantification of the mean distance of the rostral-most rostral thalamic axons to the thalamic eminence in WT $(0.82 \pm 0.08 \mathrm{~mm})$ compared with Npn $1{ }^{\text {Sema-l- }}(0.78 \pm 0.05 \mathrm{~mm})$ showed no significant difference (Mann-Whitney, two-tailed $M=60.4 ; \alpha=0.05$ ).

In contrast, axons originating from the VB complex were shifted caudally in the VTe. In these experiments, DiI was injected deep into the central third of the DT in WT and Npn $1^{\text {Sema-I- }}$ littermates (Fig. $5 E$ ). In sections $\sim 400 \mu \mathrm{m}$ caudal to the thalamic

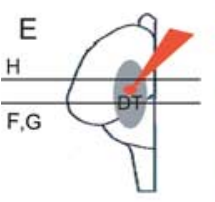

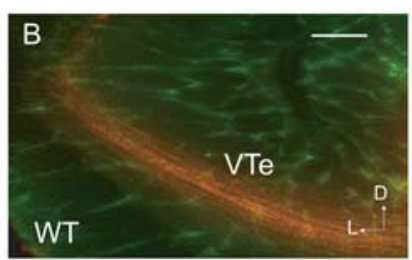
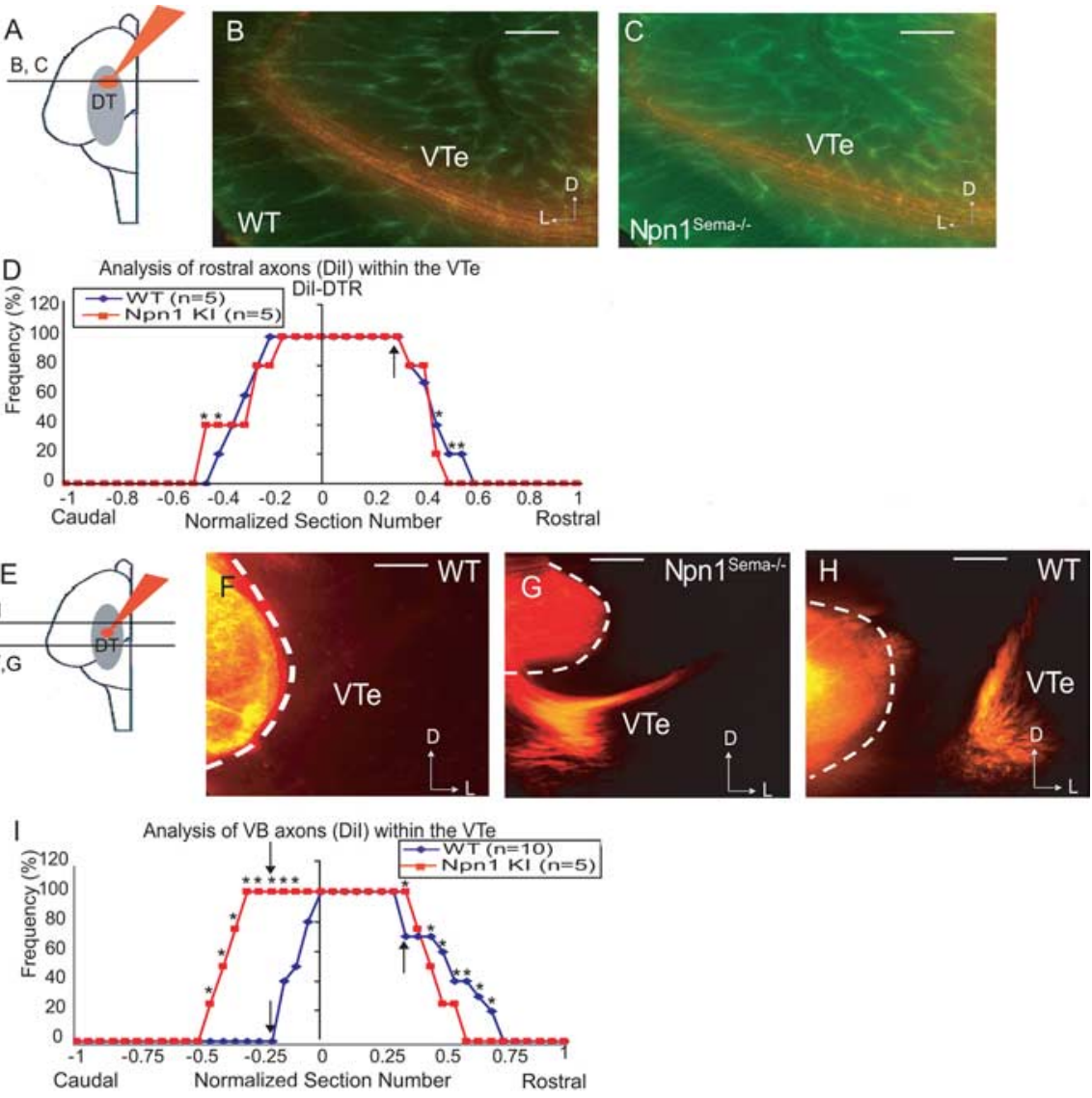

Figure 5. Npn1 binding to Sema3A is required for guidance of thalamic axons with the ventral telencephalon. $\boldsymbol{A}$, Scheme illustrating placement of Dil crystal in rostral dorsal thalamus of mouse embryos at E16.5. The line indicates level of sections at 600 $\mu \mathrm{m}$ rostral of the thalamic eminence. $\boldsymbol{B}, \boldsymbol{C}$, Images of the VTe located $600 \mu \mathrm{m}$ rostral to the thalamic eminence show the presence of rostral axons only in WT $(\boldsymbol{B})$ and Npn $1^{\text {Sema-I- }}(\boldsymbol{C}$. Scale bar, $50 \mu \mathrm{m}$. D, Quantification of the rostrocaudal distribution of rostral thalamic axons within the VTe of WT and Npn $1^{\text {Sema-I- }}$ embryos. The reference point (0) corresponds to the first section rostral axons were found was plotted versus the normalized section number along the rostrocaudal axis for both WT (blue) and $\mathrm{pn}^{\text {Sema-I- }}$ (red) mice. Asterisks indicate significance between WT and Npn $1^{\text {Sema-I- }}$ at individual points ( $p$ value $<0.05$; $F$ level of sections at $400 \mu \mathrm{m}$ caudal of the thalamic eminence $(\boldsymbol{F}, \boldsymbol{G})$ and $700 \mu \mathrm{m}$ rostral to the same reference point $(\boldsymbol{H})$. $\boldsymbol{F}-\boldsymbol{H}$ stral (red) thalamic axons were present. 4 of 5 mutant hemispheres displayed aberrant topography. Scale bar, $50 \mu \mathrm{m}$. $I$,

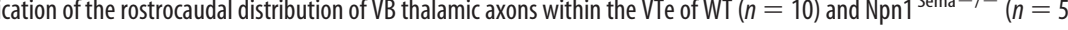
reference point (0) represents the thalamic eminence and frequency of labeled hemispheres was plotted as deAsterisks indicate significance between WT and Npn1 $1^{\text {Sema-l- }}$ at individual points ( $p<0.05 ; F$ test).

eminence no labeled axons were visible in WT VTe (Fig. 5F), whereas DiI labeled fibers were consistently observed in the VTe of Npn $1^{\text {Sema-l- }}$ mice at an equivalent level (Fig. $5 G$ ). DiI labeled fibers from the VB area of the DT were observed at more rostral levels of the WT VTe (Fig. 5H). Analysis of the distribution of labeled VB axons in the VTe confirmed that somatosensory axons from Npn $1^{\text {Sema-l- }}$ embryos were shifted caudally (Fig. 5I). Quantification of the mean distance of the caudal-most axons from the thalamic eminence was significantly greater in Npn $1^{\text {Sema-l- }}$ mutants $(0.65 \pm 0.06 \mathrm{~mm})$ compared with WT $(0.17 \pm 0.04 \mathrm{~mm})$ (Mann-Whitney, two-tailed $M=50.5, \alpha=0.1)$.

Therefore, axons from the VB complex are dependent on Npn 1 and its ability to bind Sema3A for guidance through the intermediate target. Furthermore, the caudal shift of VB thalamic axons in Npn $1^{\text {Sema-1- }}$ mutants phenocopied the shifts observed 

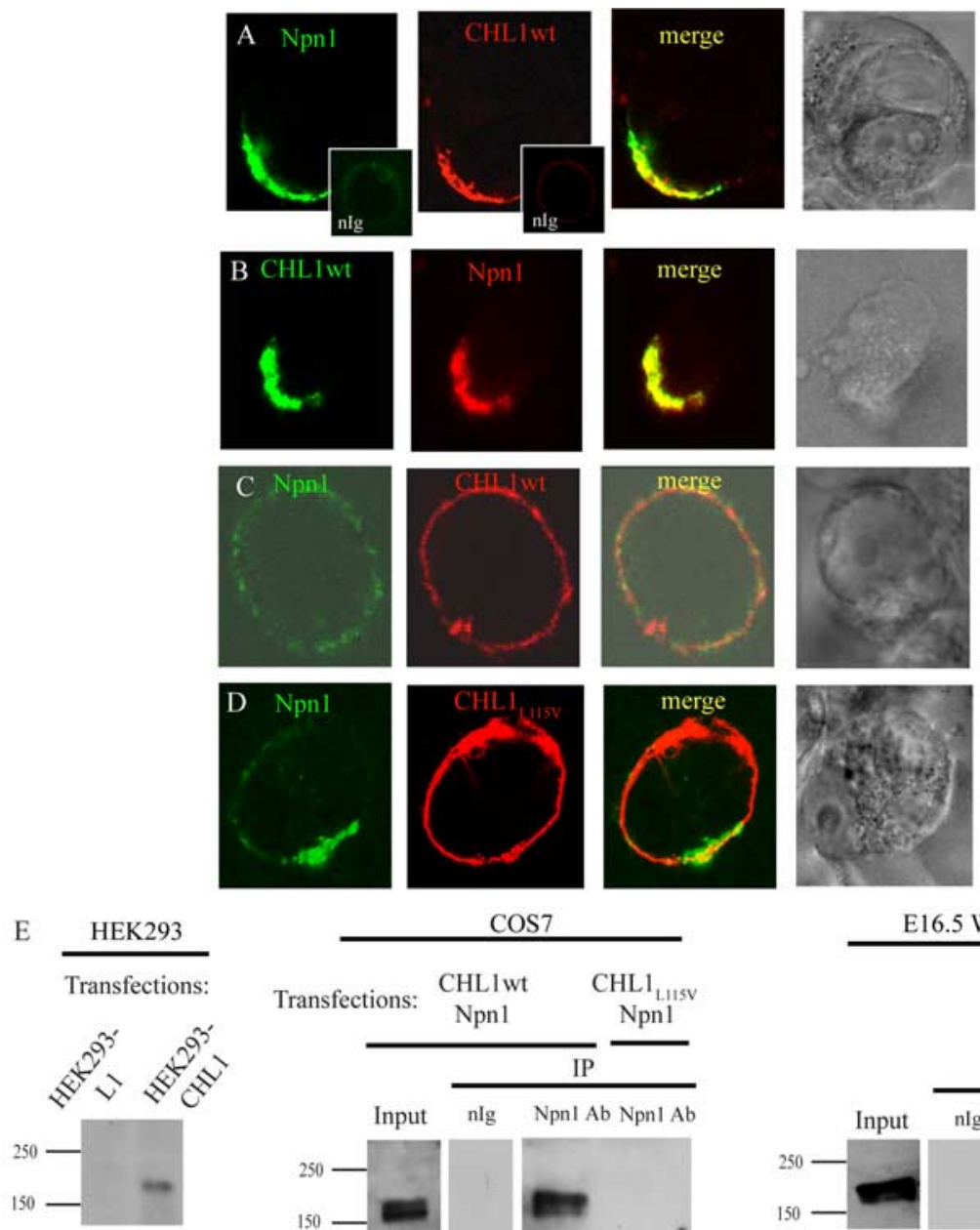

$\cos 7$

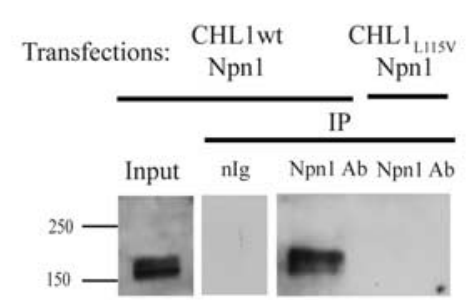

CHL1 Ab

Western Blot: CHL1 Ab Western Blot:

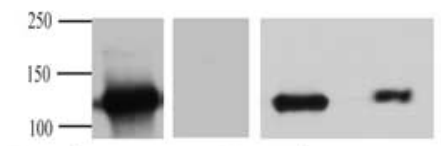

Reprobe:
E16.5 WT Brain

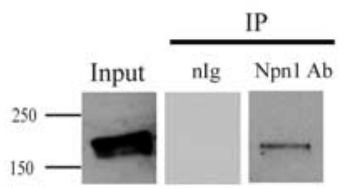

Western Blot:

CHLl Ab

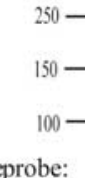

Reprobe:

in $\mathrm{CHL1}^{-}$mice, providing in vivo evidence that CHL1 and Npn1 may cooperate to control the area-specific mapping of subpopulations of thalamocortical axons.

\section{CHL1 associates with the semaphorin 3 A receptor neuropilin 1}

We next investigated whether CHL1 could form a complex with Npn1 by antibodyinduced cocapping within the plasma membrane. CHL1 and Npn1 were transiently expressed in COS-7 cells, and then Npn 1 was clustered on the cell surface by cross-linking with anti-Npn1 antibody. After fixation, Npn1 caps were detected on the cell surface by labeling with FITCsecondary antibodies and cocapping of CHL1 was observed by indirect immunofluorescence with anti-CHL1 and TRITCsecondary antibodies (Fig. 6A). Rabbit and goat nonimmune IgG antibodies were used as controls to ensure no crossreactivity of secondary antibodies (Fig. 6, insets). Cocapping of CHL1 and Npn 1 was observed on $82 \%$ of CHL1-expressing cells. In reverse cocapping experiments, CHL1 clustering induced cocapping of Npn1 in 75\% of cells (Fig. 6B). Cells treated with nonimmune rabbit IgG did not induce capping of Npn 1 or clustering of CHL1 (Fig. 6C). These results suggest that CHL1 interacts in cis- with Npn1 either directly or indirectly.

L1 associates with Npn1 through a sequence (FASNKL) in the first L1 Ig domain, within which a missense mutation (L120V) disrupts L1-Npn1, but not L1-L1 binding (Castellani et al., 2002). This conservative mutation within the FG loop of L1 results in a change in the size and shape of a surface hydrophobic residue (Bateman et al., 1996). Furthermore, the mutation of L120V in human L1 resulted in severe L1 mental retardation syndrome with hydrocephalus (De Angelis et al., 1999). Because the sequence is conserved in the Ig1 domain of CHL1 (FASNRL), we investigated whether the equivalent mutation (L115V) would prevent CHL1 interaction with Npn1 in COS-7 cells. Very little cocapping was observed (17\% of cells) between Npn1 and the $\mathrm{CHL}_{\mathrm{L} 115 \mathrm{~V}}$ mutant protein, shown by the uniform distribution of $\mathrm{CHL}_{\mathrm{L} 115 \mathrm{~V}}$ mutant protein in the plasma membrane (Fig. 6D). These results suggest that the conserved sequence, FASNRL, in Ig1 of CHL1 is necessary for Npn1 association.

The association between CHL1 and Npn1 was further explored by coimmunoprecipitation experiments. The specificity of anti-CHL1 antibody (R\&D Systems) was shown in HEK293 cells transfected 
with L1 or CHL1. CHL1 was detected only in cells transfected with CHL1 (Fig. 6E). CHL1 or $\mathrm{CHL}_{\mathrm{L} 115 \mathrm{~V}}$ were transiently cotransfected with myc-tagged Npn1 in COS-7 cells. After $2 \mathrm{~d}$, cell lysates were immunoprecipitated with an anti-myc antibody and the presence of CHL1 was analyzed by immunoblotting. CHL1 protein, expressed as a doublet of 180 (unprocessed) and 165 (mature) kiloDaltons, was detected in the immunoprecipitates of cells transfected with CHL1wt and Npn1, supporting the interaction between the two proteins (Fig. $6 E$ ). The association between CHL1 and Npn1 was dependent on the critical leucine residue in the Ig1 extracellular domain of CHL1, as $\mathrm{CHL}_{\mathrm{L} 115 \mathrm{~V}}$ was not coimmunoprecipitated with Npn1 (Fig. 6E). CHL1 also coimmunoprecipitated with Npn1 from whole-brain extracts of E16.5 WT embryos (Fig. 6E). No bands were detected in lysates immunoprecipitated with nonimmune IgG, indicating that the interaction observed was specific for Npn1 and CHL1. Western blotting of input lysates with anti-CHL1 or anti-Npn1 antibodies were used as positive controls.

\section{CHL1 is required for Sema3A-induced} growth cone collapse of thalamic axons To investigate whether CHL1 is required for growth cone collapse of thalamic axons in response to Sema3 A, genetic rescue experiments were performed in which cultures of dissociated thalamic neurons from $\mathrm{CHL}^{-}{ }^{-}$embryos (E14.5) were transfected with plasmids encoding CHL1wt, mutant $\mathrm{CHL}_{\mathrm{L} 115 \mathrm{~V}}$, defective in Npn-1 binding, or empty vector, together with a GFP expression plasmid. After $3 \mathrm{~d}$, cells were treated with Sema3A-AP or control Fc-AP. Cellular actin was stained with phalloidin and GFP-expressing cells were scored for growth cone collapse by phalloidin fluorescence. Cotransfection was efficient, as the percentage of GFP-positive neurons expressing $\mathrm{CHL} 1$ or $\mathrm{CHL}_{\mathrm{L} 115 \mathrm{~V}}$ was 84 and $81 \%$, respectively. $\mathrm{CHL}^{-}$neurons transfected with vector alone showed a small but significant growth cone collapse response to Sema3A-AP compared with Fc-AP control (Fig. $7 A, B, G$ ). The percentage of collapsed growth cones in CHL1 cultures did not change when Fc-AP was added (data not shown). In $\mathrm{CHL}^{-}{ }^{-}$thalamic neurons transfected with CHL1wt cDNA, the growth cone collapse response to Sema3A-AP greatly increased over control Fc-AP (Fig. 7C,D, G). Strikingly, transfection of $\mathrm{CHL}_{1}{ }^{-}$neurons with the $\mathrm{CHL}_{\mathrm{L} 115 \mathrm{~V}}$-expressing plasmid did not increase the growth cone collapse response to Sema3A (Fig. $7 E, F)$. The smaller Sema3A collapse response that remained in $\mathrm{CHL}_{1}{ }^{-}$and $\mathrm{CHL}_{\mathrm{L} 115 \mathrm{~V}}$-expressing cultures compared with treatment with Fc-AP (Fig. 7G) was not significantly
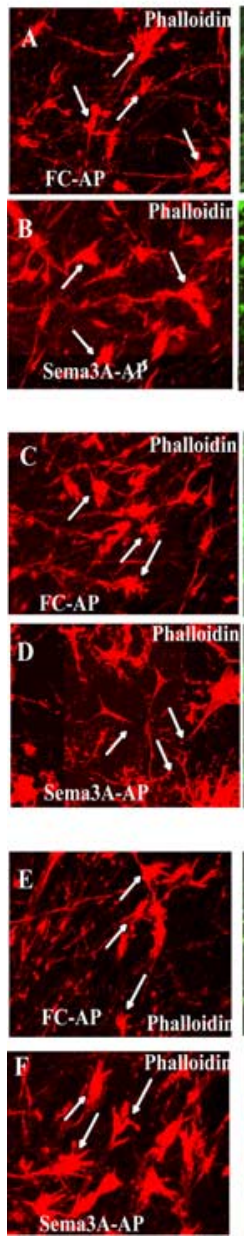
antibodies.
$\mathrm{CHL1}^{+}$
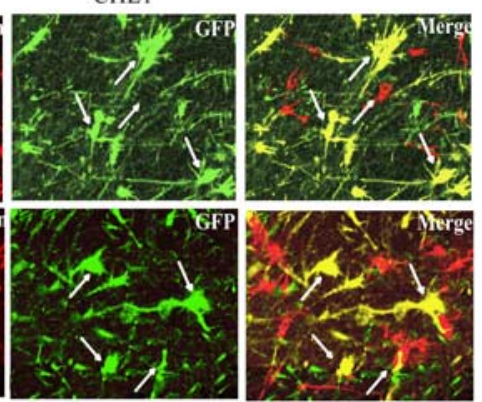

CHLIwt
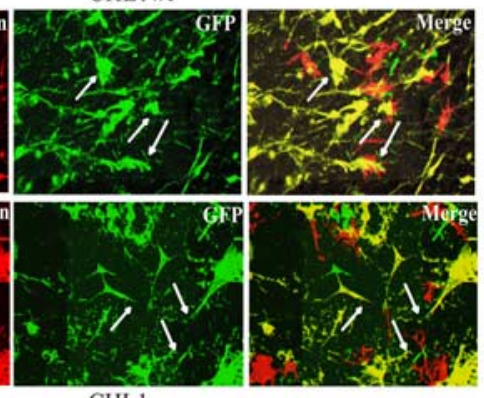

$\mathrm{CHL1}_{\text {L.IISV }}$
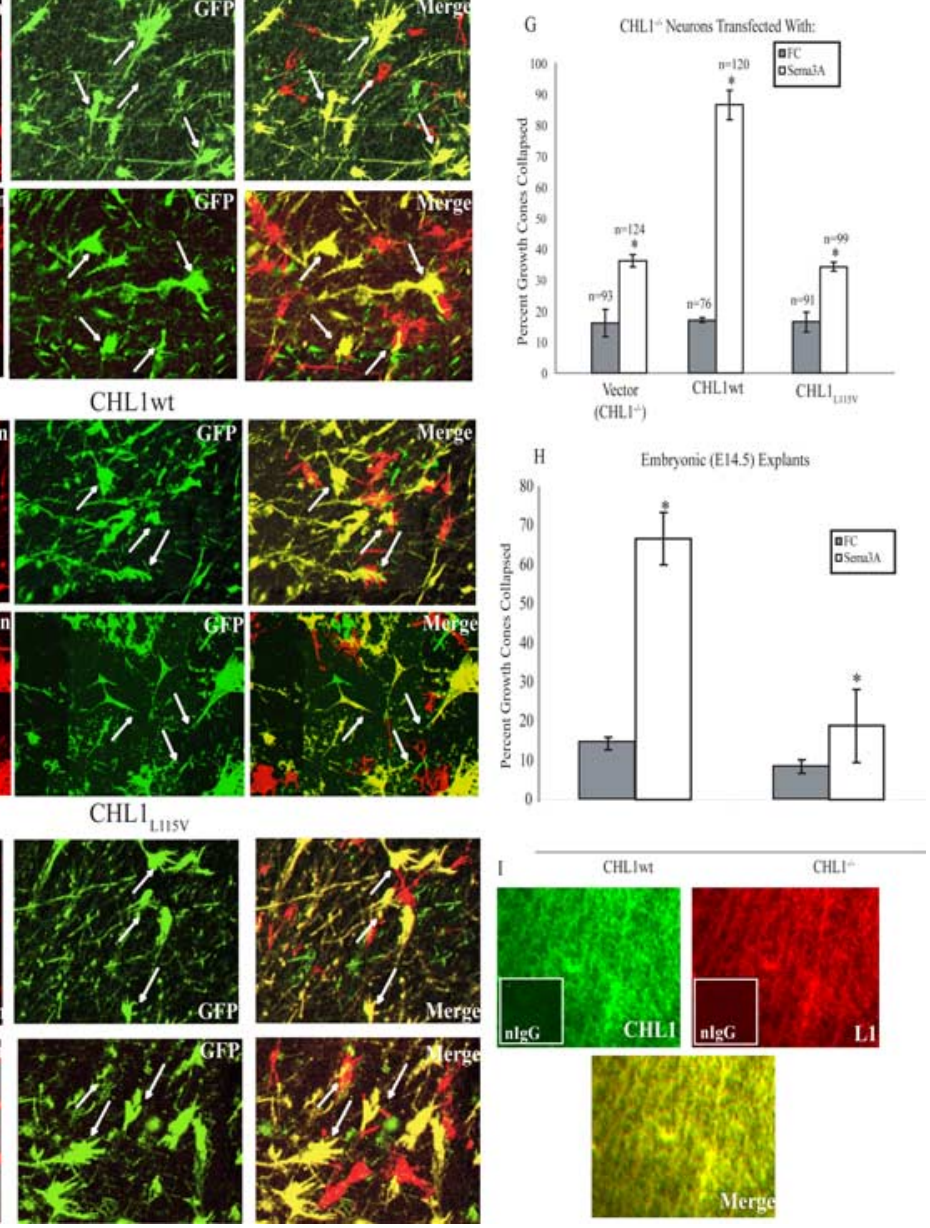

Figure 7. $C H L 1$ is required for the growth cone collapsing effects of semaphorin $3 A$ in cultures of thalamic neurons (E14.5). $\boldsymbol{A}$, $\boldsymbol{C}, \boldsymbol{E}$, Growth cones of dissociated thalamic neurons from $\mathrm{CHL1}^{-}$embryos (E14.5) transfected with empty vector (A), CHL1wt (C), or $\mathrm{CHL}_{\mathrm{L} 115 \mathrm{~V}}$ mutant $(\boldsymbol{E})$ were not collapsed in response to $\mathrm{Fc}-\mathrm{AP}$ fusion protein. Filamentous actin is shown in the first panel demonstrated by phalloidin staining. Transfected neurons (GFP) are shown in the middle. The last panel illustrates the merged images. Only neurons expressing GFP were included in the analysis. Noncollapsed growth cones are indicated with white arrows. $\boldsymbol{B}, \boldsymbol{D}, \boldsymbol{F}$, Sema3A had little effect on the growth cones of neurons expressing no $\mathrm{CHL} 1(\boldsymbol{B})$ and or the mutant form, $\mathrm{CHL}_{\mathrm{L} 115 \mathrm{~V}}(\boldsymbol{F})$ and most growth cones are not collapsed (white arrows). However, growth cones of $\mathrm{CHL}^{-}$thalamic neurons transfected with CHL1wt (D) were collapsed after treatment with $30 \mathrm{~nm}$ Sema3A-AP fusion protein (white arrows). G, Quantification of percent growth cones collapsed from thalamic neurons in response to Sema3A. Sema3A significantly increased the percentage of collapsed CHL1wt-expressing growth cones compared with Fc-AP (asterisk indicates significance, $p=0.005$ ). Although Sema3A had a significantly reduced effect on growth cones expressing no $\mathrm{CHL} 1$ or $\mathrm{CHL}_{\mathrm{L} 115 \mathrm{~V}}$, Sema3A did significantly increase growth cone collapse compared with control (asterisk indicates significance; $\left.\mathrm{CHL}^{-1-}, p=0.035 ; \mathrm{CHL}_{\mathrm{L} 115 \mathrm{v}}, p=0.04\right)$. $\boldsymbol{H}$, Sema3A significantly increased the percentage of collapsed growth cones in WT explants isolated from the caudal half of the dorsal thalamus ( $n=57$ growth cones). Sema3A had only marginal effects on growth cone collapse of CHL1 ${ }^{-}$caudal explants $(n=48)$; however, it did significantly increase growth cone collapse compared with control. No differences were observed in the percentage of collapsed growth cones treated with control Fc-AP. Asterisk indicates significance at two-tailed $t$ test $(p<0.05)$. I, Double immunofluorescence staining for CHL1 (green) and L1 (red) in coronal sections of WT brain at E14.5 through ventral regions of the DT. CHL1 colocalized with L1 in many but not all fibers within the DT (shown in yellow in merge), consistent with the location of thalamocortical fibers. Nonimmune lgG antibodies were used to demonstrate minimal cross-reactivity of the secondary

different in $\mathrm{CHL1}^{-}$and mutant-expressing neurons, and might represent an L1/Npn1-dependent mechanism. In explant cultures containing nondissociated neurons from embryonic thalamus (E14.5), Sema3A-AP similarly induced robust growth cone collapse of thalamic axons from WT embryos but was much less effective at collapsing $\mathrm{CHL}^{-}{ }^{-}$thalamic axons (Fig. $7 \mathrm{H}$ ).

CHL1 (Liu et al., 2000; present study) and L1 (Ohyama et al., 2004; Wiencken-Barger et al., 2004) are each expressed in the dorsal thalamus during thalamocortical projection. Coexpres- 
sion of CHL1 and L1 in the dorsal thalamus was investigated by double immunofluorescence staining during thalamocortical outgrowth (E14.5). Coronal sections through ventral regions of the dorsal thalamus show CHL1 and L1 mostly colocalized on fibers within this region (Fig. 7I). Although data presented here indicates that CHL1 mediates the major response of Sema3Ainduced growth cone collapse at least at this stage, it remains open whether L1 contributes to Sema3A-induced growth cone collapse in a portion of thalamic axons.

These results indicate that CHL1 is responsible for a majority of the Sema3A-induced growth cone collapse in embryonic thalamic axons at this stage, and that a single point mutation within the Npn 1 binding site in CHL1 Ig1 domain is critical for rescuing the response in $\mathrm{CHL}_{1}{ }^{-}$thalamic neurons. These data support a mechanism in which CHL1 associates with Npn1 through the CHL1 Ig1 domain to form a receptor complex for Sema3A, important for growth cone collapse of thalamic axons that could regulate guidance in the VTe.

\section{Discussion}

Here, we identify CHL1 as a new molecular determinant of thalamocortical axon projection to specific neocortical areas, acting within an intermediate target, the VTe. CHL1 deletion disrupted the final thalamocortical map by causing a contingent of axons from somatosensory thalamic nuclei to incorrectly target the visual cortex. CHL1 colocalized with Npn1 on thalamic axons, and axonal tracing demonstrated that somatosensory thalamic axons of both $\mathrm{CHL}^{-}$and Sema3A-nonresponsive $\mathrm{Npn} 1^{\text {Sema-I- }}$ mutants misprojected caudally within the VTe, consistent with loss of repellent axon guidance to the high-caudal to low-rostral Sema3A gradient (Fig. 8). This mechanism is supported by genetic rescue experiments in $\mathrm{CHL}^{-}$thalamic neurons, which demonstrated that a single point mutation (L115V) in the CHL1 Ig1 domain was critical for both Sema3A-induced growth cone collapse and association of CHL1 with Npn1 on the cell surface. Our results reveal a novel cooperation between CHL1 and Npn 1 for repellent axon guidance responsible for sorting of specific thalamocortical projections at the VTe in response to Sema3A.

The aberrant caudal shift of VB thalamic axons in the VTe of $\mathrm{CHL}^{-}$and Npn $1^{\text {Sema-l- }}$ mice is consistent with a cooperative function for CHL1 and Npn1 in mediating axon repulsion from the descending caudal gradient of Sema3A in the VTe. The caudal shift of VB thalamic axons in the $\mathrm{CHL1}^{-}$telencephalon culminates in misrouting of these axons to the posterior visual cortex. A number of mutant axons misguided in the telencephalon, may be lost during later stages of development before barrel field formation, as a substantial proportion of VB axons correctly targeted the somatosensory cortex, potentially accounting for the relatively normal barrel field in $\mathrm{CHL}^{-}$mice. Mice deficient in Sema3A (Ulupinar et al., 1999) or PlexinA4, a Npn1 coreceptor (Suto et al., 2005), display relatively normal barrels as well. CHL1 probably does not factor in the tangential migration of cells that form a permissive corridor for thalamocortical axon navigation into the telencephalon (Lopez-Bendito et al., 2006), as CHL1 transcripts were not detected in the ganglionic eminence. The ability of CHL1 to promote Sema3A-induced growth cone collapse in thalamic neurons mediated by an identified Npn1 binding site in the CHL Ig1 domain supports the interpretation that VB thalamic axons are repelled from Sema3A in the caudal VTe.

The high ventral to low dorsal gradient of CHL1 in the dorsal thalamus is consistent with preferential expression of CHL1 in somatosensory VB nuclei. Similarly, plexinA4, a component of

\section{Wild Type}
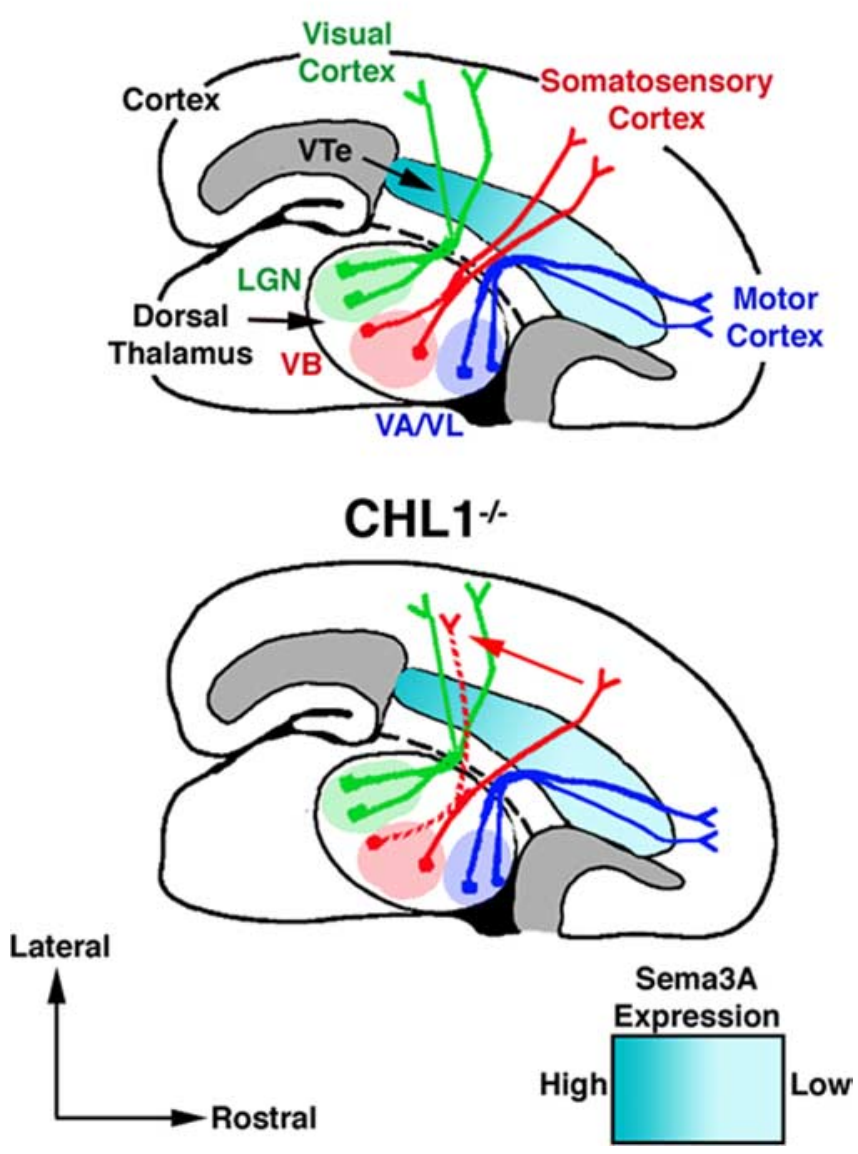

Figure 8. CHL1 and Npn1 mediates guidance of thalamocortical axons at the VTe. A model for mapping and final targeting of thalamocortical axons in WT and $\mathrm{CHL} 1^{-1-}$ mice is shown. WT and $\mathrm{CHL}^{-}{ }^{-}$axons from the motor thalamic nuclei (VA/VL) project to the motor cortex (blue lines). WT axons from the ventral basal complex (VB) project to the somatosensory cortex (solid red line). Deletion of CHL1 causes a contingent of these axons to shift caudally in the VTe because of lack of repulsion by the high concentration of Sema3A in this region. These misguided axons inappropriately target the visual cortex (red dashed line). Axons from the LGN target the visual cortex in both WT and $\mathrm{CHL}_{1}{ }^{-}$mice (green lines).

the Sema3A signaling complex, is preferentially expressed in VPM/VPL nuclei of the VB complex (Suto et al., 2005). These expression patterns may account for the selective effect of loss of $\mathrm{CHL} 1 / \mathrm{Npn} 1$ on projection of somatosensory thalamic axons.

Cocapping and coimmunoprecipitation studies demonstrated that CHL1 and Npn1 associate directly or indirectly within the plasma membrane through a critical leucine residue within a motif $\left(F_{A S N R L}{ }^{115}\right)$ in the CHL1 Ig1 domain. This motif is homologous to the Npn1 binding site of L1 (FASNKL), which is required for Sema3A-induced growth cone collapse in neonatal cortical and sensory neurons (Castellani et al., 2000). The significant decrease in Sema3A-induced growth cone collapse response in $\mathrm{CHL}^{-}{ }^{-}$or mutant-expressing cultures suggests that CHL1 mediates the major Sema3A-induced growth cone collapse response at this stage of development. Because this response was relatively small at this stage in development $(\sim 25 \%)$, it would not be expected to significantly increase the severity of the phenotype observed in Npn1 $1^{\text {Sema-l- }}$ embryos. The residual Sema3Adependent growth cone collapse observed in $\mathrm{CHL}^{-}$or $\mathrm{CHL}_{\mathrm{L} 115 \mathrm{~V}}$-expressing thalamic neurons may be caused by Npn 1 signaling through L1, or it may indicate a requirement for both 
CHL1 and L1 in a subpopulation of neurons. Sema3C binding sites have been observed on thalamic axons (Bagnard et al., 1998), thus it cannot be ruled out that L1 or CHL1 convey preferential responsiveness to different class 3 semaphorins. Despite their similar roles in mediating Sema3A-induced growth cone collapse, genetic deletion of CHL1 or L1 causes different thalamocortical phenotypes in vivo. Thalamocortical axons in $\mathrm{L}^{-}$mice are hyperfasciculated but normally target the motor, somatosensory, and visual cortex (Ohyama et al., 2004; Wiencken-Barger et al., 2004), whereas thalamocortical axons of $\mathrm{CHL}^{-}{ }^{-}$mice are not altered in fasciculation at the VTe or cortex but do show misrouting of somatosensory projections. Differential expression of CHL1 and L1 in thalamic neuron subpopulations or interaction with different homophilic and heterophilic partners along the thalamocortical pathway might account for these differences. It is also possible that L1 might functionally compensate for loss of CHL1 in certain subpopulations of thalamic neurons.

Because of decreased viability of $\mathrm{Npn} 1^{\text {Sema-/- }}$ mice postnatally, it has not been determined whether loss of Sema3 A binding to Npn1 perturbs the final thalamocortical map. Npn1 binds Sema3A, 3C, and, to a lesser extent, other semaphorins; thus, future thalamocortical mapping studies in Sema3A null mutant mice will be needed to ascertain whether Sema3A is the major ligand responsible for sorting of VB thalamic axons in the VTe. Limited axon tracing studies in one strain of Sema3A knock-out mice $(\mathrm{C} 57 \mathrm{BL} / 6)$ showed that thalamic axon terminals reached layer IV of the somatosensory cortex, but topographic guidance and mistargeting to other cortical areas were not studied (Catalano et al., 1998). Another Sema3A knock-out strain (C57BL/6) displayed axon guidance defects, but were not examined for thalamocortical projections.

Our results do not exclude additional roles for CHL1 and Npn1 as mediators of cortical cues involved in thalamocortical axon targeting. Sema3A is expressed in the cortex, where diverse semaphorins display transient and regionally specific patterns of expression corresponding to distinct periods of axon growth, radial invasion, and synaptic targeting (Skaliora et al., 1998). Furthermore, because CHL1 is expressed on corticofugal axons, some aspects of thalamocortical misrouting in $\mathrm{CHL}^{-}$mice might be secondary to corticothalamic misprojections based on the handshake hypothesis (Molnar et al., 1998), which postulates corticofugal axons act as reciprocal guides for thalamocortical axons in the VTe. This scenario is unlikely based on the observation that corticofugal axon outgrowth was unaffected by loss of CHL1 from the DTe (supplemental Fig. 1, available at www.jneurosci.org as supplemental material). Likewise, it is doubtful that CHL1 mediates direct apposition between thalamocortical and corticothalamic axons in the VTe, because these populations remained segregated and tightly fasciculated en route to the neocortex in CHL1 ${ }^{-}$embryos (supplemental Fig. 2, available at www.jneurosci.org as supplemental material).

EphrinA5 is an important axon guidance cue identified previously to influence thalamocortical axon sorting at the VTe (Dufour et al., 2003). The high caudal gradient of ephrinA5 in the VTe preferentially regulates sorting of rostral thalamic axons, ensuring targeting to the motor cortex. We demonstrate that CHL1 and Npn 1 mediate sorting of VB but not rostral thalamic axons, specifying targeting to the somatosensory cortex. The rostrocaudal expression levels of Sema3A, ephrinA5, and their receptors may render CHL1/Npn1 the predominant guidance system for VB axon sorting at the VTe. Differential expression of plexinAs (Yaron et al., 2005), MICALs (molecules interacting with CASL) (Pasterkamp et al., 2006), or RanBPM (Togashi et al.,
2006), which bind Npn1, might also influence CHL1 interaction with Npn1 and downstream signaling. Caudal thalamic axons might rely on other guidance factors for rostrocaudal sorting in the VTe, for example netrin-1 (Braisted et al., 2000) or other semaphorins. Indeed, dorsoventral guidance of caudal, but not rostral, thalamocortical axons is altered in the VTe of Sema6Adeficient mice, where axons fail to turn up through the internal capsule, instead projecting down to the amygdala (Leighton et al., 2001).

Semaphorins and Npns are regulators of repulsive axon guidance through the nervous system, where they are important for pathfinding and fasciculation of olfactory, spinal and cranial axons, and other major tracts (Kitsukawa et al., 1997; Giger et al., 2000; Cloutier et al., 2002; Gu et al., 2003) Our study extends the role of Sema3A and Npn1 to the thalamocortical pathway, one of the main topographic projections in the brain. The results further reveal a prominent new role for CHL1 as a coreceptor for Npn1 mediating axon guidance to Sema3A in the VTe, vital for establishment of area-specific thalamocortical projections.

\section{References}

Agmon A, Yang LT, Jones EG, O’Dowd DK (1995) Topological precision in the thalamic projection to neonatal mouse barrel cortex. J Neurosci 15:549-561.

Altman JA, Bayer SA (1995) Atlas of prenatal rat brain development. Tokyo: CRC.

Bagnard D, Lohrum M, Uziel D, Puschel AW, Bolz J (1998) Semaphorins act as attractive and repulsive guidance signals during the development of cortical projections. Development 125:5043-5053.

Bagnard D, Chounlamountri N, Puschel AW, Bolz J (2001) Axonal surface molecules act in combination with semaphorin 3a during the establishment of corticothalamic projections. Cereb Cortex 11:278-285.

Bateman A, Jouet M, MacFarlane J, Du JS, Kenwrick S, Chothia C (1996) Outline structure of the human L1 cell adhesion molecule and the sites where mutations cause neurological disorders. EMBO J 15:6050-6059.

Bonnin A, Torii M, Wang L, Rakic P, Levitt P (2007) Serotonin modulates the response of embryonic thalamocortical axons to netrin-1. Nat Neurosci 10:588-597.

Boyd JD, Matsubara JA (1996) Laminar and columnar patterns of geniculocortical projections in the cat: relationship to cytochrome oxidase. J Comp Neurol 365:659-682.

Braisted JE, Catalano SM, Stimac R, Kennedy TE, Tessier-Lavigne M, Shatz CJ, O'Leary DD (2000) Netrin-1 promotes thalamic axon growth and is required for proper development of the thalamocortical projection. J Neurosci 20:5792-5801.

Cang J, Kaneko M, Yamada J, Woods G, Stryker MP, Feldheim DA (2005) Ephrin-as guide the formation of functional maps in the visual cortex. Neuron 48:577-589.

Castellani V, Chedotal A, Schachner M, Faivre-Sarrailh C, Rougon G (2000) Analysis of the L1-deficient mouse phenotype reveals cross-talk between Sema3A and L1 signaling pathways in axonal guidance [see comments]. Neuron 27:237-249.

Castellani V, De Angelis E, Kenwrick S, Rougon G (2002) Cis and trans interactions of L1 with neuropilin-1 control axonal responses to semaphorin 3A. EMBO J 21:6348-6357.

Catalano SM, Messersmith EK, Goodman CS, Shatz CJ, Chedotal A (1998) Many major CNS axon projections develop normally in the absence of semaphorin III. Mol Cell Neurosci 11:173-182.

Chen S, Mantei N, Dong L, Schachner M (1999) Prevention of neuronal cell death by neural adhesion molecules L1 and CHL1. J Neurobiol 38:428-439.

Cloutier JF, Giger RJ, Koentges G, Dulac C, Kolodkin AL, Ginty DD (2002) Neuropilin-2 mediates axonal fasciculation, zonal segregation, but not axonal convergence, of primary accessory olfactory neurons. Neuron 33:877-892.

Colbert MC, Rubin WW, Linney E, LaMantia AS (1995) Retinoid signaling and the generation of regional and cellular diversity in the embryonic mouse spinal cord. Dev Dyn 204:1-12.

De Angelis E, MacFarlane J, Du JS, Yeo G, Hicks R, Rathjen FG, Kenwrick S, 
Brummendorf T (1999) Pathological missense mutations of neural cell adhesion molecule L1 affect homophilic and heterophilic binding activities. EMBO J 18:4744-4753.

Demyanenko G, Tsai A, Maness PF (1999) Abnormalities in neuronal process extension, hippocampal development, and the ventricular system of L1 knockout mice. J Neurosci 19:4907-4920.

Demyanenko GP, Schachner M, Anton E, Schmid R, Feng G, Sanes J, Maness PF (2004) Close homolog of L1 modulates area-specific neuronal positioning and dendrite orientation in the cerebral cortex. Neuron 44:423-437.

Dufour A, Seibt J, Passante L, Depaepe V, Ciossek T, Frisen J, Kullander K, Flanagan JG, Polleux F, Vanderhaeghen P (2003) Area specificity and topography of thalamocortical projections are controlled by ephrin/Eph genes. Neuron 39:453-465.

Falk J, Bechara A, Fiore R, Nawabi H, Zhou H, Hoyo-Becerra C, Bozon M, Rougon G, Grumet M, Puschel AW, Sanes JR, Castellani V (2005) Dual functional activity of semaphorin $3 \mathrm{~B}$ is required for positioning the anterior commissure. Neuron 48:63-75.

Flanagan JG, Leder P (1990) The kit ligand: a cell surface molecule altered in steel mutant fibroblasts. Cell 63:185-194.

Garel S, Yun K, Grosschedl R, Rubenstein JL (2002) The early topography of thalamocortical projections is shifted in Ebf1 and Dlx1/2 mutant mice. Development 129:5621-5634.

Ghosh A, Shatz CJ (1993) A role for subplate neurons in the patterning of connections from thalamus to neocortex. Development 117:1031-1047.

Ghosh A, Antonini A, McConnell SK, Shatz CJ (1990) Requirement for subplate neurons in the formation of thalamocortical connections. Nature 347:179-181.

Giger RJ, Cloutier JF, Sahay A, Prinjha RK, Levengood DV, Moore SE, Pickering S, Simmons D, Rastan S, Walsh FS, Kolodkin AL, Ginty DD, Geppert M (2000) Neuropilin-2 is required in vivo for selective axon guidance responses to secreted semaphorins. Neuron 25:29-41.

Gu C, Rodriguez ER, Reimert DV, Shu T, Fritzsch B, Richards LJ, Kolodkin AL, Ginty DD (2003) Neuropilin-1 conveys semaphorin and VEGF signaling during neural and cardiovascular development. Dev Cell 5:45-57.

Hamasaki T, Leingartner A, Ringstedt T, O'Leary DD (2004) EMX2 regulates sizes and positioning of the primary sensory and motor areas in neocortex by direct specification of cortical progenitors. Neuron 43:359-372.

Hevner RF, Miyashita-Lin E, Rubenstein JL (2002) Cortical and thalamic axon pathfinding defects in Tbr1, Gbx2, and Pax6 mutant mice: evidence that cortical and thalamic axons interact and guide each other. J Comp Neurol 447:8-17.

Hillenbrand R, Molthagen M, Montag D, Schachner M (1999) The close homologue of the neural adhesion molecule L1 (CHL1): patterns of expression and promotion of neurite outgrowth by heterophilic interactions. Eur J Neurosci 11:813-826.

Katz LC, Crowley JC (2002) Development of cortical circuits: lessons from ocular dominance columns. Nat Rev Neurosci 3:34-42.

Kawasaki T, Kitsukawa T, Bekku Y, Matsuda Y, Sanbo M, Yagi T, Fujisawa H (1999) A requirement for neuropilin-1 in embryonic vessel formation. Development 126:4895-4902.

Kitsukawa T, Shimizu M, Sanbo M, Hirata T, Taniguchi M, Bekku Y, Yagi T, Fujisawa H (1997) Neuropilin-semaphorin III/D-mediated chemorepulsive signals play a crucial role in peripheral nerve projection in mice. Neuron 19:995-1005.

Leighton PA, Mitchell KJ, Goodrich LV, Lu X, Pinson K, Scherz P, Skarnes WC, Tessier-Lavigne M (2001) Defining brain wiring patterns and mechanisms through gene trapping in mice. Nature 410:174-179.

Leshchyns'ka I, Sytnyk V, Richter M, Andreyeva A, Puchkov D, Schachner M (2006) The adhesion molecule CHL1 regulates uncoating of clathrincoated synaptic vesicles. Neuron 52:1011-1025.

Liu Q, Dwyer ND, O'Leary DD (2000) Differential expression of COUPTFI, CHL1, and two novel genes in developing neocortex identified by differential display PCR. J Neurosci 20:7682-7690.

Lopez-Bendito G, Cautinat A, Sanchez JA, Bielle F, Flames N, Garratt AN, Talmage DA, Role LW, Charnay P, Marin O, Garel S (2006) Tangential neuronal migration controls axon guidance: a role for neuregulin-1 in thalamocortical axon navigation. Cell 125:127-142.
Ma L, Harada T, Harada C, Romero M, Hebert JM, McConnell SK, Parada LF (2002) Neurotrophin-3 is required for appropriate establishment of thalamocortical connections. Neuron 36:623-634.

Maness PF, Schachner M (2007) Neural recognition molecules of the immunoglobulin superfamily: signal transducers of axons guidance and neuronal migration. Nat Neurosci 10:19-26.

Molnar Z, Adams R, Blakemore C (1998) Mechanisms underlying the early establishment of thalamocortical connections in the rat. J Neurosci 18:5723-5745.

Montag-Sallaz M, Schachner M, Montag D (2002) Misguided axonal projections, neural cell adhesion molecule 180 mRNA upregulation, and altered behavior in mice deficient for the close homolog of L1. Mol Cell Biol 22:7967-7981.

Nikonenko AG, Sun M, Lepsveridze E, Apostolova I, Petrova I, Irintchev A, Dityatev A, Schachner M (2006) Enhanced perisomatic inhibition and impaired long-term potentiation in the CA1 region of the juvenile CHL1deficient mice. Eur J Neurosci 23:1839-1852.

Ohyama K, Tan-Takeuchi K, Kutsche M, Schachner M, Uyemura K, Kawamura K (2004) Neural cell adhesion molecule L1 is required for fasciculation and routing of thalamocortical fibres and corticothalamic fibres. Neurosci Res 48:471-475.

Okabe M, Ikawa M, Kominami K, Nakanishi T, Nishimune Y (1997) 'Green mice' as a source of ubiquitous green cells. FEBS Lett 407:313-319.

Pasterkamp RJ, Dai HN, Terman JR, Wahlin KJ, Kim B, Bregman BS, Popovich PG, Kolodkin AL (2006) MICAL flavoprotein monooxygenases: expression during neural development and following spinal cord injuries in the rat. Mol Cell Neurosci 31:52-69.

Polleux F, Ghosh A (2002) A The slice overlay assay: a versatile tool to study the influence of extracellular signals on neuronal development. Sci STKE 2002:L9.

Seibt J, Schuurmans C, Gradwhol G, Dehay C, Vanderhaeghen P, Guillemot F, Polleux F (2003) Neurogenin2 specifies the connectivity of thalamic neurons by controlling axon responsiveness to intermediate target cues. Neuron 39:439-452.

Shimogori T, Grove EA (2005) Fibroblast growth factor 8 regulates neocortical guidance of area-specific thalamic innervation. J Neurosci 25:6550-6560.

Skaliora I, Singer W, Betz H, Puschel AW (1998) Differential patterns of semaphorin expression in the developing rat brain. Eur J Neurosci 10:1215-1229.

Suto F, Ito K, Uemura M, Shimizu M, Shinkawa Y, Sanbo M, Shinoda T, Tsuboi M, Takashima S, Yagi T, Fujisawa H (2005) Plexin-a4 mediates axon-repulsive activities of both secreted and transmembrane semaphorins and plays roles in nerve fiber guidance. J Neurosci 25:3628-3637.

Tamamaki N, Fujimori K, Nojyo Y, Kaneko T, Takauji R (2003) Evidence that Sema3A and Sema3F regulate the migration of GABAergic neurons in the developing neocortex. J Comp Neurol 455:238-248.

Togashi H, Schmidt EF, Strittmatter SM (2006) RanBPM contributes to Semaphorin3A signaling through plexin-A receptors. J Neurosci 26:4961-4969.

Torii M, Levitt P (2005) Dissociation of corticothalamic and thalamocortical axon targeting by an EphA7-mediated mechanism. Neuron 48:563-575.

Tuttle R, Nakagawa Y, Johnson JE, O'Leary DD (1999) Defects in thalamocortical axon pathfinding correlate with altered cell domains in Mash-1deficient mice. Development 126:1903-1916.

Ulupinar E, Datwani A, Behar O, Fujisawa H, Erzurumlu R (1999) Role of semaphorin III in the developing rodent trigeminal system. Mol Cell Neurosci 13:281-292.

Villegas G, Tufro A (2002) Ontogeny of semaphorins 3A and 3F and their receptors neuropilins 1 and 2 in the kidney. Mech Dev 119 Suppl $1: S 149-153$.

Wiencken-Barger AE, Mavity-Hudson J, Bartsch U, Schachner M, Casagrande VA (2004) The role of L1 in axon pathfinding and fasciculation. Cereb Cortex 14:121-131.

Yaron A, Huang PH, Cheng HJ, Tessier-Lavigne M (2005) Differential requirement for Plexin-A3 and -A4 in mediating responses of sensory and sympathetic neurons to distinct class 3 Semaphorins. Neuron 45:513523. 